\title{
Integrative Profiling of Amyotrophic Lateral Sclerosis Lymphoblasts Identifies Unique Metabolic and Mitochondrial Disease Fingerprints
}

Teresa Cunha-Oliveira ( $\nabla$ teresa.oliveira@cnc.uc.pt)

Center for Neuroscience and Cell Biology: CNC.IBILI https://orcid.org/0000-0002-7382-0339

Marcelo Carvalho

Center for Neuroscience and Cell Biology: CNC.IBILI

Vilma Sardão

Center for Neuroscience and Cell Biology: CNC.IBILI

Elisabete Ferreiro

Center for Neuroscience and Cell Biology: CNC.IBILI

Débora Mena

Center for Neuroscience and Cell Biology: CNC.IBILI

Francisco B. Pereira

Polytechnic Institute of Coimbra: Instituto Politecnico de Coimbra

Fernanda Borges

University of Porto: Universidade Do Porto

Paulo J. Oliveira

Center for Neuroscience and Cell Biology: CNC.IBILI

Filomena S.G. Silva

Center for Neuroscience and Cell Biology: CNC.IBILI

\section{Research Article}

Keywords: Amyotrophic lateral sclerosis, mitochondria, bioenergetics, cellular metabolism, superoxide dismutase 1

Posted Date: January 5th, 2022

DOI: https://doi.org/10.21203/rs.3.rs-1196454/v1

License: @ (1) This work is licensed under a Creative Commons Attribution 4.0 International License. Read Full License 


\section{Abstract}

Amyotrophic lateral sclerosis (ALS) is a devastating neurodegenerative disease with a rapid progression and no effective treatment. Metabolic and mitochondrial alterations in peripheral tissues of ALS patients may present diagnostic and therapeutic interest. We aimed to identify mitochondrial fingerprints in lymphoblast from ALS patients harboring SOD1 mutations (mutSOD1) or with unidentified mutations (undSOD1), compared with age/sex matched controls.

Three groups of lymphoblasts, from mutSOD1 or undSOD1 ALS patients and age/sex-matched controls, were obtained from Coriell Biobank and divided into 3 age/sex-matched cohorts. Mitochondria-associated metabolic pathways were analyzed using Seahorse MitoStress and ATP Rate assays, complemented with metabolic phenotype microarrays, metabolite levels, gene expression, and protein expression and activity. Pooled (all cohorts) and paired (intra-cohort) analyses were performed by using bioinformatic tools, and the features with higher information gain values were selected and used for principal component analysis and Naïve Bayes classification.

Pooled analysis revealed that undSOD1 patients had statistically higher glycolytic ATP production rate and lower Tfam protein content compared to controls, which were also the experimental features highlighted by multidimensional analysis. Metabolic phenotypic profiles in lymphoblasts from ALS patients with mutSOD1 and undSOD1 revealed unique age-dependent different substrate oxidation profiles. For most parameters, different patterns of variation were found between cohorts, which may be due to age or sex.

In the present work, we investigated several metabolic and mitochondrial hallmarks in lymphoblasts from each donor and, although a high heterogeneity of results was found, we identified specific metabolic and mitochondrial fingerprints that may have a diagnostic and therapeutic interest.

\section{Introduction}

Amyotrophic lateral sclerosis (ALS) disease, the most common motor neuron disorder [1-3] is characterized by motor neuron degeneration, progressive muscle atrophy, and paralysis that ultimately leads to death [4], without a disease-modifying treatment [5-8]. The disease affects people between 51 and 66 years of age, on average, with a survival time, from symptoms onset to death, between 24 and 50 months [1]. Approximately $90-95 \%$ of ALS cases are sporadic (sALS), with unknown etiology and no prior family history [9]. The remaining patients develop familial ALS (fALS) [9], which is inherited and associated with an earlier age of onset $[5,10]$. Growing evidence demonstrates that fALS and sALS can be triggered by common pathological mechanisms, presenting similar clinical features $[10,9,11]$. Several molecular mechanisms play a potential role in the disease development, including altered RNA metabolism, glutamate excitotoxicity, protein misfolding and aggregation, endoplasmic reticulum stress, disrupted protein trafficking, defective axonal transport, oxidative stress, inflammation, and mitochondrial dysfunction [12, 13, 2, 3, 14]. Which events are causative of the disease rather than a consequence is still unknown. In particular, mitochondrial dysfunction is considered to play a fundamental role in ALS progression, and multiple mitochondrial alterations have been described not only on the central nervous system (CNS) of ALS patients but also in peripheral tissues, such as skeletal muscle [15, 16], liver [17] and lymphocytes [18]. Indeed, the disruption of mitochondrial structure, dynamics, bioenergetics, and calcium buffering has been reported in ALS patients, in vitro and in vivo ALS models $[9,19]$.

Conclusions: A considerable number of genes were identified as being disease-modifying [20]. One of the most studied genes in ALS research, implicated in both forms of ALS, is SOD1, which encodes for the Cu/Zn superoxide dismutase 1 (SOD1) protein [21-24]. SOD1 is a metalloprotein responsible for eliminating superoxide anion radicals, localized mainly in the cytosol and found in the nucleus, peroxisomes, and mitochondria [23]. Alterations in mitochondrial respiration have been extensively described in mutant SOD1 (mutSOD1) mouse models [25-30] and in ALS patients with mutSOD1 [26, 31]. Although there is evidence of SOD1 accumulation in mitochondria [25,32-36], the real function of this enzyme in this organelle remains unclear. Most studies suggest that wild-type and mutSOD1 accumulate mainly in the mitochondrial intermembrane space (IMS) [25, 32-34, 36], although mutSOD1 was also shown to be localized on the outer mitochondrial membrane (OMM) [37, 38], associated with proteins such as B-cell lymphoma 2 (Bcl-2) [38] and voltage-dependent anion-selective channel (VDAC) [39], or accumulate in the mitochondrial matrix [40]. Contradictory results can be found in the literature concerning the effect of mutSOD1 in the mitochondrial electron transport chain (ETC) activity. Increased complex I activity in the frontal cortex [31] and in the motor and parietal cortex [26] were described in patients carrying mutSOD ${ }^{\mathrm{A} 4 \mathrm{~V}}$. In these patients, activities of complexes II-III were also increased in the motor cortex and cerebellum, in motor and parietal cortex, also occurring in the cerebellum from a single patient with mutSOD1 ${ }^{11 \mathrm{II}}{ }^{\mathrm{T}}$, as well as in motor cortex and cerebellum of ALS patients with no mutSOD1 identified to date [26]. Thus, it is possible that the increased ETC activity represents a compensatory mechanism resulting from oxidative damage to the IMM, which can result in the uncoupling of oxidative phosphorylation [41]. In postmortem spinal cord tissues from sALS patients, mitochondrial impairment related to the decrease in complexes I, II, III and IV activities was shown to be associated with a reduction in mtDNA content and citrate synthase activity [42]. Conversely, no alteration in ETC activity was found in crude mitochondrial preparations of motor, parietal cortex and cerebellum [26]. These contradictory findings can be explained by a more pronounced impairment of ETC function in spinal cord when compared to brain tissue, by a small number of samples analyzed in both studies, and by the heterogeneity of sALS patients [43]. Altered ETC activities were also detected in non-neuronal tissues, such as reduced complex I and IV activities in skeletal muscle [42, 44] and reduced complex I activity, together with lower ATP levels, in lymphocytes [45]. Increased mitochondrial membrane potential $\left(\Delta \Psi_{\mathrm{m}}\right)$ in fibroblasts from sALS patients [46, 47] may indicate a compensatory mechanism to rescue inefficient ATP synthesis, although further studies are needed to confirm these variations. Importantly, although there is strong evidence of a general mitochondrial dysfunction in ALS, whether this represents a cause or a consequence of other intracellular toxic mechanisms remains to be elucidated [9]. In sum, metabolism plays a crucial role in ALS pathogenesis, and mitochondrial dysfunction is likely to be one of the earliest pathophysiological events in ALS [9]. Further research is needed to allow patient stratification and find fingerprints and therapeutic targets for ALS based on mitochondrial metabolism. Because ALS is a multisystemic disease, lymphoblasts have been increasingly used to study metabolic characterization in ALS since they share molecular mechanisms, especially mitochondrial dysfunction, with degenerated neurons [48]. Lymphoblasts enable the analysis of multiple variables from the same biological source, allowing identifying internal biological correlations and testing personalized therapeutics. In the present study, we identified mitochondrial 
fingerprints in lymphoblasts from ALS patients harboring SOD1 mutations (mutSOD1) or with still unidentified SOD1 mutations (undSOD1), compared to their age and sex matched controls. This study describes the potential role of circulating mitochondrial disruption markers in patient stratification, and identifies targets for developing novel disease-modifying drug candidates.

\section{Materials And Methods}

\section{Cell selection/ Experimental design}

Lymphoblast cell lines, established by Epstein-Barr transformation, from 3 patients with mutSOD1 and 3 patients without identified SOD1 mutations (undSOD1), and 3 controls of the same age and sex were obtained from the cell line repository at Coriell Institute for Medical Research, USA (www.coriell.org). The groups were divided into 3 cohorts, each containing 1 sample from healthy control, 1 sample from one undSOD1 patient and 1 sample from one mutSOD1 patient: C1-Females 46 years old; C2- Males 46 years old; C3-Males 26/27 years old (Table 1).

Table 1

List of cell samples and known characteristics

\begin{tabular}{|c|c|c|c|c|c|c|c|c|c|}
\hline & Sample & Control_C1 & undSOD1_C1 & $\underset{\mathrm{C} 1}{\operatorname{mutSOD1}}$ & Control_C2 & undSOD1_C2 & ${ }_{\mathrm{C} 2}^{\text {mutSOD1_ }}$ & Control_C3 & undSOD1_C \\
\hline & Coriell Reference & ND14405 & ND16061 & ND13750 & ND05102 & ND12215 & ND10941 & ND07879 & ND11570 \\
\hline & RRID & CVCL_GL09 & CVCL_BS65 & CVCL_BP71 & CVCL_IB49 & CVCL_BJ76 & CVCL_BF63 & CVCL_IC97 & CVCL_BH1: \\
\hline & Sex & $\mathrm{F}$ & $\mathrm{F}$ & $\mathrm{F}$ & M & M & $M$ & M & $M$ \\
\hline & Age & 46 & 46 & 46 & 46 & 46 & 46 & 26 & 27 \\
\hline & Description & Control & $\begin{array}{l}\text { Patient with } \\
\text { ALS }\end{array}$ & $\begin{array}{l}\text { Patient with } \\
\text { ALS }\end{array}$ & Control & $\begin{array}{l}\text { Patient with } \\
\text { ALS }\end{array}$ & $\begin{array}{l}\text { Patient } \\
\text { with ALS }\end{array}$ & Control & $\begin{array}{l}\text { Patient witr } \\
\text { ALS }\end{array}$ \\
\hline & $\begin{array}{l}\text { Identified } \\
\text { mutations }\end{array}$ & ND & ND & $\begin{array}{l}\text { mutSOD1: } \\
\text { ALA4VAL }\end{array}$ & ND & ND & $\begin{array}{l}\text { mutSOD1: } \\
\text { ILE113THR }\end{array}$ & ND & ND \\
\hline Signs & UMN signs bulbar & ND & Y & & & $\mathrm{Y}$ & & & Y \\
\hline diagnosis & $\begin{array}{l}\text { UMN signs } \\
\text { cervical/upper } \\
\text { limbs }\end{array}$ & ND & Y & Y & & Y & & & Y \\
\hline & $\begin{array}{l}\text { UMN signs } \\
\text { thoracic chest }\end{array}$ & ND & IND & & & ND & & & ND \\
\hline & $\begin{array}{l}\text { UMN signs } \\
\text { lumbosacral/lower } \\
\text { limbs }\end{array}$ & ND & Y & Y & & Y & Y & & Y \\
\hline & LMN signs bulbar & ND & Y & & & Y & & & \\
\hline & $\begin{array}{l}\text { LMN signs } \\
\text { cervical/upper } \\
\text { limbs }\end{array}$ & ND & Y & & & $\mathrm{Y}$ & & & Y \\
\hline & $\begin{array}{l}\text { LMN signs } \\
\text { thoracic chest }\end{array}$ & ND & ND & & & ND & & & \\
\hline & $\begin{array}{l}\text { LMN signs } \\
\text { lumbosacral/lower } \\
\text { limbs }\end{array}$ & ND & ND & $\mathrm{Y}$ & & $\mathrm{Y}$ & $Y$ & & Y \\
\hline $\begin{array}{l}\text { EMG } \\
\text { studies }\end{array}$ & Bulbar & ND & ND & ND & & $\begin{array}{l}\text { Chronic } \\
\text { denervation }\end{array}$ & ND & & ND \\
\hline & $\begin{array}{l}\text { cervical/upper } \\
\text { limbs }\end{array}$ & ND & $\begin{array}{l}\text { Acute } \\
\text { chronic } \\
\text { denervation }\end{array}$ & $\begin{array}{l}\text { Acute } \\
\text { chronic } \\
\text { denervation }\end{array}$ & & $\begin{array}{l}\text { Acute/ } \\
\text { Chronic } \\
\text { denervation }\end{array}$ & $\begin{array}{l}\text { Acute/ } \\
\text { Chronic } \\
\text { denervation }\end{array}$ & & $\begin{array}{l}\text { Acute/ } \\
\text { Chronic } \\
\text { denervation }\end{array}$ \\
\hline & thoracic chest & ND & ND & $\begin{array}{l}\text { Acute } \\
\text { denervation }\end{array}$ & & ND & $\begin{array}{l}\text { Acute } \\
\text { denervation }\end{array}$ & & $\begin{array}{l}\text { Acute/ } \\
\text { Chronic } \\
\text { denervation }\end{array}$ \\
\hline & $\begin{array}{l}\text { lumbosacral/lower } \\
\text { limb }\end{array}$ & ND & ND & $\begin{array}{l}\text { Acute } \\
\text { chronic } \\
\text { denervation }\end{array}$ & & $\begin{array}{l}\text { Acute/ } \\
\text { Chronic } \\
\text { denervation }\end{array}$ & $\begin{array}{l}\text { Acute/ } \\
\text { Chronic } \\
\text { denervation }\end{array}$ & & $\begin{array}{l}\text { Acute/ } \\
\text { Chronic } \\
\text { denervation }\end{array}$ \\
\hline
\end{tabular}

\section{Cell culture}

Lymphoblasts were grown in RPMI 1640 medium from Sigma-Aldrich (Saint Louis, USA, R6504) supplemented with $2 \mathrm{~g} / \mathrm{L}$ sodium bicarbonate, 15\% (v/v) fetal bovine serum and $0.5 \%(\mathrm{v} / \mathrm{v})$ of penicillin-streptomycin plus amphotericin B in T25 or T75 flasks, in an upright position, at $37^{\circ} \mathrm{C}$ in a humidified atmosphere of 
$5 \% \mathrm{CO}_{2}$. The cells were kept in culture at a density of 0.4 to $1.2 \times 10^{6}$ cells $/ \mathrm{mL}$ and counted using a Bio-Rad® TC20 Automated Cell Counter (Bio-Rad, Hercules, CA, USA). For cell counting, $10 \mu \mathrm{L}$ of each cellular suspension was diluted in 0.4\% Trypan blue solution from Gibco (Hampton, USA, $15250-061)$ in a ratio $1: 1$.

Every 2-3 days, the cultures were diluted and re-fed with fresh medium according to the rate of cell growth and the required number of cells needed for the experiments, and once per week, the medium was renewed entirely after cell centrifugation. Before all experiments, lymphoblasts were plated at 0.4 or $0.7 \mathrm{x}$ $10^{6} \mathrm{cells} / \mathrm{mL}$ in RPMI medium and incubated for $48 \mathrm{~h}$ or $24 \mathrm{~h}$, respectively, to secure a cell density of around $1 \times 10^{6} \mathrm{cell} / \mathrm{mL}$ in each assay. Considering that doubling times can affect cell phenotype and responses, cells were discarded after 30 population doublings from the initial culture provided by Coriell, and new cultures were started from aliquots frozen at low cell passage.

\section{Real-time cell metabolic analysis}

Cellular oxygen consumption and extracellular acidification were measured at $37^{\circ} \mathrm{C}$ using an XFe96 Extracellular Flux Analyzer (Agilent Technologies, Inc. Santa Clara, CA, USA). Cells were seeded in XF96 cell culture microplates, pre-coated with $0.1 \mathrm{mg} / \mathrm{mL}$ of poly-D-lysine hydrobromide. For the coating, we added to each well $30 \mu \mathrm{L}$ of a solution $(0.1 \mathrm{mg} / \mathrm{mL})$ of poly-D-lysine hydrobromide (Sigma-Aldrich, Ref. P7280, Lot SLBW6178) and let it rest for $2 \mathrm{~h}$ at $37^{\circ} \mathrm{C}$. After, we rinsed each well with Milli-Q water and placed the plate at $4^{\circ} \mathrm{C}$, in sterile conditions, to use the next day.

\section{Lymphoblast seeding in poly-D-lysine pre-coated XF96 cell culture microplates}

On the day of the assay, lymphoblasts were centrifuged at $259 \mathrm{xg}$ for $4 \mathrm{~min}$. The supernatant was discarded, and cells were resuspended in $1 \mathrm{~mL}$ of respective assay media. Cell density was determined using a TC20 $0^{\mathrm{TM}}$ automated cell counter (Bio-Rad Laboratories, Inc. CA,USA). Cells were diluted in assay media at a $3.2 \times 10^{6}$ cell $/ \mathrm{mL}$ density, and $50 \mu \mathrm{L}$ of the cell suspension was added to each well. For the background wells, $50 \mu \mathrm{L}$ of assay media was added. Following, 125 $\mu \mathrm{L}$ of assay media was added to all the wells, and the plate was centrifuged at $200 \mathrm{xg}$ for 1 min with no brake. After centrifugation, we confirmed cell adherence to the well bottom and placed the plate in a non- $\mathrm{CO}_{2}$ incubator at $37^{\circ} \mathrm{C}$ for $1 \mathrm{~h}$ before the assay.

\section{Mitochondrial Bioenergetics analysis}

Mitochondrial bioenergetics analysis was performed in serum-free RPMI medium (Agilent Seahorse XF RPMI Medium, Ref. 103336-100, Lot. 35517002) supplemented with $2 \mathrm{mM}$ glutamine and $11 \mathrm{mM}$ glucose and $\mathrm{pH}$ adjusted to 7.4 .

The XF96 sensor cartridge was hydrated in $200 \mu \mathrm{L} /$ well of Agilent Seahorse XF Calibrant (Agilent Seahorse XF Calibrant, Ref. 100840-000) at $37^{\circ} \mathrm{C}$ in a non$\mathrm{CO}_{2}$ incubator $18 \mathrm{~h}$ before the assay.

The assay used to evaluate mitochondrial bioenergetics consists of 3 serial injections of oligomycin, FCCP, and rotenone/antimycin A. Selected optimized concentrations of oligomycin, FCCP, and rotenone/antimycin A were respectively $3 \mu \mathrm{M}, 0.25 \mu \mathrm{M}$, and $1 \mu \mathrm{M}$. Normalization was performed by the number of the cells seeded in each well. The mitochondrial bioenergetics-related parameters were analyzed using the Agilent Seahorse XF Cell Mitostress test report generator software (version 2.6.0).

\section{Real-Time ATP production rate assay}

Real-Time ATP production rate assay was performed in serum-free RPMI medium (Agilent Seahorse XF RPMI Medium, Ref. 103336-100, Lot. 35517002) supplemented with $2 \mathrm{mM}$ glutamine, $10 \mathrm{mM}$ glucose, $1 \mathrm{mM}$ sodium pyruvate, and $1 \mathrm{mM}$ HEPES, pH 7.4. The XF96 sensor cartridge was hydrated in 200 $\mu \mathrm{L} /$ well of Agilent Seahorse XF Calibrant (Agilent Seahorse XF Calibrant, Ref. 100840-000) at $37^{\circ} \mathrm{C}$ in a non- $\mathrm{CO}_{2}$ incubator, $18 \mathrm{~h}$ before the assay.

Real-Time ATP production rate assay consists of a sequential injection of oligomycin $(3 \mu \mathrm{M})$ and a mixture of rotenone/antimycin $\mathrm{A}(1 \mu \mathrm{M}$ of each inhibitor). Normalization was performed by the number of the cells seeded. The XF real-time ATP rate assay parameters were calculated using the Agilent Seahorse XF real-time ATP rate report generator software (version 2.6.0).

\section{Metabolic microarrays}

The metabolic microarrays were performed using the Biolog MitoPlate S-1 system (Biolog, Hayward, CA, USA), which contained triplicate wells for 31 different substrates of mitochondrial or glycolytic metabolism dried and pre-coated into the wells (rows $\mathrm{A}-\mathrm{B}$ cytoplasmic, rows $\mathrm{C}-\mathrm{H}$ mitochondrial) plus three negative wells (no substrate).

On the day of the assay, $30 \mu \mathrm{L}$ of assay mix composed by Biolog mitochondrial assay solution (MAS) 2x (\#72303, Lot 0722191), Redox dye MC 2x (\#74353, Lot 198019) and saponin $100 \mu \mathrm{g} / \mathrm{mL}$ (SAE0073, Sigma Aldrich) were added to each well of MitoPlate, and incubated for $1 \mathrm{~h}$, at $37^{\circ} \mathrm{C}$. Lymphoblasts were centrifuged at $259 \mathrm{xg}$ for $4 \mathrm{~min}$, resuspended in $1 \mathrm{~mL}$ of Biolog MAS 1x, and cell density was determined using a TC20 $0^{\mathrm{TM}}$ automated cell counter (Bio-Rad Laboratories, Inc. CA, USA). Lymphoblasts were resuspended at $5.3 \times 10^{6}$ cells $/ \mathrm{mL}$ in Biolog MAS $1 \mathrm{x}$, and $30 \mu \mathrm{L}$ of the cell suspension was added to each well. The plates were sealed and then incubated in an OmniLog phenotypic microarray system for $6 \mathrm{~h}$ for kinetic analysis, with 5 min intervals. The maximal rate was calculated in the linear phase (first $4 \mathrm{~h}$ ), using the data analysis ${ }^{\circledR} 1.7$ software (Biolog Hayward, CA, USA).

\section{Analysis of gene expression}

Total RNA was extracted from dry pellets containing $\sim 5 \times 10^{6}$ cells using RNeasy mini-kit (Qiagen, Düsseldorf, Germany), following the manufacturer's protocols, and quantified using a Nanodrop 2000 (ThermoScientific, Waltham, MA, USA), confirming that the A260/280 ratio was higher than 1.9. RNA was converted into cDNA using the iScript cDNA synthesis kit (Bio-Rad, Hercules, CA, USA), following the manufacturer's instructions. RT-PCR was performed using the SsoFast EvaGreen Supermix, in a CFX96 real time-PCR system (Bio-Rad, Hercules, CA, USA), with the primers defined in Table 2, at 500 nM. Amplification of $12.5 \mathrm{ng}$ of cDNA was performed with an initial cycle of $30 \mathrm{~s}$ at $95.0^{\circ} \mathrm{C}$, followed by 40 cycles of $5 \mathrm{~s}$ at $95^{\circ} \mathrm{C}$ plus $5 \mathrm{~s}$ at the annealing temperature (Ta) 
shown in Table 2. At the end of each cycle, EvaGreen fluorescence was recorded to enable the determination of Cq. After amplification, the melting temperatures of the PCR products were determined by performing melting curves. For each set of primers, amplification efficiency was assessed using ten-fold dilutions of a pool of all samples, and no template and no transcriptase controls were ran. Relative normalized expression was determined by the CFX 96 Manager software (v. 3.0; Bio-Rad), using TBP, YWHAZ, PUM1 and B2M as reference genes.

Table 2

List of primers

\begin{tabular}{|c|c|c|c|c|}
\hline Gene & Accession number & Fwd primer & Rev Primer & Ta \\
\hline NDUFA9 & NM_005002 & GCCTATCGATGGGTAGCAAGAG & TGAGTTCCAGTGGTGTTGCC & 60 \\
\hline SDHA & NM_004168 & CGGGTCCATCCATCGCATAAG & TATATGCCTGTAGGGTGGAACTGAA & 60 \\
\hline UQCRC2 & NM_003366 & TTCAGCAATTTAGGAACCACCC & GGTCACACTTAATTTGCCACCAA & 60 \\
\hline CYCS & NM_018947 & CGTTGAAAAGGGAGGCAAGC & TCCCCAGATGATGCCTTTGTTC & 60 \\
\hline coX4i1 & NM_001861 & GAGAAAGTCGAGTTGTATCGCA & GCTTCTGCCACATGATAACGA & 60 \\
\hline ATP5G & NM_001002027 & GGCTAAAGCTGGGAGACTGAAA & GTGGGAAGTTGCTGTAGGAAGG & 60 \\
\hline TFAM & NM_003201 & GTTTCTCCGAAGCATGTG & GGTAAATACACAAAACTGAAGG & 60 \\
\hline G6PD & NM_000402 & AGGCCGTGTACACCAAGATG & AGGGAGCTTCACGTTCTTGT & 63 \\
\hline PDHA1 & NM_000284 & TTGCTGCTGCCTATTGTA & CGTGTACGGTAACTGACT & 60 \\
\hline PDK1 & NM_002610 & CCAGGACAGCCAATACAA & CTCGGTCACTCATCTTCAC & 60 \\
\hline PFKM & NM_000289 & AGAGTTACCGTAATGGGCGG & TCAGCCACCACTGTTCCTTG & 63 \\
\hline PFKP & NM_001242339 & TGGAGTGGATCACTGCAAAACT & TTTGGGAATCCTGTGCTCAA & 60 \\
\hline GLS & NM_014905 & СCTGTGGCATGTATGACTTC & CAGAGAAACAAGATCGTGACAA & 60 \\
\hline PUM1 & NM_014676 & GCAAAGATGGACCAAAAGGA & ATTGGCTGGGAAACTGAATG & 59 \\
\hline TBP & NM_003194 & CGAATATAATCCCAAGCGGTTTGC & AGCTGGAAAACCCAACTTCTGT & 60 \\
\hline B2M & NM_004048 & GGCTATCCAGCGTACTCCAA & AGTCAACTTCAATGTCGGATGG & 60 \\
\hline YWHAZ & NM_003406 & TGTAGGAGCCCGTAGGTCATC & GTGAAGCATTGGGGATCAAGA & 58 \\
\hline ND5 & NC_012920.1 (12337-14148) & AGTTACAATCGGCATCAACCAA & CCCGGAGCACATAAATAGTATGG & 60 \\
\hline$B 2 M\left({ }^{*} \mathrm{gDNA}\right)$ & NC_000015.10 & TGTTCCTGCTGGGTAGCTCT & ССТССАTGATGCTGCTTACA & 60 \\
\hline
\end{tabular}

\section{Analysis of mtDNA copy number by quantitative real-time PCR}

Lymphoblast cell lines were collected and centrifuged at $259 \times \mathrm{g}$ for $5 \mathrm{~min}$. The pellets were washed in $5 \mathrm{~mL}$ of PBS, and the suspension was centrifuged at $259 \mathrm{xg}$ for $5 \mathrm{~min}$. The resulting pellets were stored at $-80^{\circ} \mathrm{C}$ until DNA extraction. Total DNA was extracted from dry pellets containing $\sim 5 \times 10^{6}$ cells using the QIAamp DNA mini-kit (Qiagen, Düsseldorf, Germany), following the manufacturer's protocols and quantified using a Nanodrop 2000 (ThermoScientific, Waltham, MA, USA). DNA was sonicated for $10 \mathrm{~min}$ to avoid dilution bias, and RT-PCR was performed using the SsoFast EvaGreen Supermix, in a CFX96 real time-PCR system (Bio-Rad, Hercules, CA, USA), with the primers defined in Table 2, at $500 \mathrm{nM}$. Amplification of $25 \mathrm{ng}$ DNA was performed with an initial cycle of $2 \mathrm{~min}$ at $98^{\circ} \mathrm{C}$, followed by 40 cycles of $5 \mathrm{~s}$ at $98^{\circ} \mathrm{C}$ plus $5 \mathrm{~s}$ at $60^{\circ} \mathrm{C}$. At the end of each cycle, EvaGreen fluorescence was recorded to enable the determination of Cq. For quality control, no template controls were run, and the melting temperature of the PCR products was determined after amplification by performing melting curves. To assess amplification efficiency and inter-run calibration, ten-fold dilutions of one sample were run in all plates. mtDNA copy number was determined in each sample by the relative quantities of the mitochondrial gene ND5 and the B2M single-copy nuclear gene, using the CFX 96 Manager software (v. 3.0; Bio-Rad).

\section{Mitochondrial transmembrane potential}

The $\Delta \psi_{m}$ was assessed by measuring tetramethylrhodamine methyl ester perchlorate (TMRM, \#T668, Invitrogen) fluorescence by flow cytometry. TMRM is a lipophilic cationic dye that accumulates within mitochondria in inverse proportion to $\Delta \psi \mathrm{m}$ according to the Nernst equation [49]. For that purpose, $3 \times 10^{6}$ cells in suspension of each lymphoblast cell line were centrifuged at $259 \mathrm{xg}$, at room temperature, for $5 \mathrm{~min}$. The supernatant was then discarded, and the pellet resuspended in $900 \mu \mathrm{L}$ of phosphate-buffered saline (PBS, containing $137 \mathrm{mM} \mathrm{NaCl}, 2.7 \mathrm{mM} \mathrm{KCl} 1.4 \mathrm{mM} \mathrm{K}_{2} \mathrm{HPO}_{4}$, and $4.3 \mathrm{mM} \mathrm{KH}_{2} \mathrm{PO}_{4}$, at pH 7.4) and volume equally distributed into 3 microtubes. Afterwards, cells of the first microtube were kept at $37^{\circ} \mathrm{C}$, for 15 min, in the dark (control condition for fluorescence background), while cells in the other two microtubes were incubated with TMRM (at a final concentration of $100 \mathrm{nM}$ ) in the same conditions as the control microtube. At the end of this incubation period, FCCP (at a final concentration of $1 \mu \mathrm{M}$ ) was added to cells in one of the TMRM-treated microtubes. As an uncoupler, FCCP induces mitochondrial depolarization, thus determining the mitochondrial potential baseline for each cell sample. Fluorescence was collected through a $585 / 40 \mathrm{~nm}$ bandpass filter in the FL2 channel of an Accuri ${ }^{\text {TM }}$ C6 flow cytometer (Becton Dickinson), equipped with an argon blue laser (488 $\mathrm{nm}$ ). Data analysis was performed using FlowJo X software (v10.7.1; Becton, Dickinson \& Company). First, doublets and cell debris were gated out. A gate for lymphoblasts was established in the control condition (fluorescence background) and applied to the corresponding TMRM and TMRM+FCCP plots. An average of 30000 events, corresponding to lymphoblasts with TMRM fluorescence, were analyzed. Arithmetic mean values of the background fluorescence 
signal (in arbitrary units) were then subtracted to mean values of TMRM fluorescence. Finally, mean fluorescence values in FCCP-treated lymphoblasts were subtracted to mean values of fluorescence in its absence, thus resulting in indirect measurements of mitochondrial membrane potential. These values were used in the graphic representation and statistical analysis for each experimental condition.

\section{Western Blotting}

Total cellular extracts were obtained from a volume of cell suspension containing $30 \times 10^{6}$ cells of each sample, which was centrifuged at $259 \times \mathrm{g}$, at room temperature, for $5 \mathrm{~min}$, and the resulting pellet was washed once with PBS. The cellular pellet was resuspended in cell lysis buffer containing $20.4 \mathrm{mM}$ ethylenediaminetetraacetic acid (EDTA), $146.9 \mathrm{mM}$ ethyleneglycol-bis (2-aminoethylether) $\mathrm{N}, \mathrm{N},{ }^{\prime} \mathrm{N},{ }^{\prime} \mathrm{N}$ - tetraacetic acid (EGTA), 1 mM calcium glycerophosphate, $1 \mathrm{mM}$ sodium orthovanadate, $2.6 \mathrm{mM}$ sodium pyrophosphate, $20.4 \mathrm{mM}$ Tris- $\mathrm{HCl}$ and 1\% ( $\mathrm{v} / \mathrm{v}$ ) Triton X-100, supplemented with $0.1 \mathrm{mM}$ phenylmethanesulfonylfluoride (PMSF), 12\% (v/v) protease inhibitor cocktail (Sigma \#P8340), 1 mM dithiothreitol (DTT), 10 mM nicotinamide (NAM) and 20 $\mathrm{mM}$ sodium fluoride. The protein content of each sample was then determined by the Bradford method [50]. Laemmli buffer $6 \mathrm{x}$ (composed by $188 \mathrm{mM}$ Tris$\mathrm{HCl}, 2.2 \mathrm{mM}$ sodium dodecyl sulfate (SDS), $0.03 \%(\mathrm{w} / \mathrm{v})$ bromophenol blue and $79 \%(\mathrm{v} / \mathrm{v})$ glycerol) was added $50 \mu \mathrm{g}$ of protein samples that were then denatured at $95^{\circ} \mathrm{C}$ for $5 \mathrm{~min}$. Samples containing $50 \mu \mathrm{g}$ protein were separated by $12 \%$ polyacrylamide gel electrophoresis and electrophoretically transferred to a PVDF membrane. Then, the membranes were stained with Ponceau S (P3504, Sigma Aldrich), a reliable method for total protein normalization in western blotting [51]. After membrane blocking with 5\% nonfat dry milk (Bio-Rad) in Tris-Buffered Saline Tween (TBS-T; 50 mM Tris-HCl, pH 8; 154 mM NaCl and 0.1\% (v/v) Tween 20) for $2 \mathrm{~h}$ at room temperature under continuous stirring, membranes were incubated overnight at $4^{\circ} \mathrm{C}$, under stirring, with the antibodies polyclonal goat anti-Tfam (1:750, sc-23588, RRID:AB_2303230, Santa Cruz), polyclonal rabbit anti-PGC1a (1:1000, sc-13067, RRID:AB_2166218, Santa Cruz) or polyclonal rabbit anti-TOM20 (1:5000, sc-11415, RRID:AB_2207533, Santa Cruz). Once incubation was complete, membranes were incubated with horseradish peroxidase (HRP)- conjugated secondary antibodies goat anti-rabbit (1:1000, \#7074, RRID:AB_2099233, Cell Signaling) and mouse anti-goat (1:750, sc-2354, RRID:AB_628490, Santa Cruz) for $1 \mathrm{~h}$ at room temperature under continuous agitation. Membranes were incubated with ECL (\#1705061, BioRad) and imaged using a VWR® Gel Documentation System Imager Chemi 5QE (VWR, USA). Band density was measured using the TotalLab TL120v2008 software (Newcastle, UK).

\section{Intracellular ATP levels}

Intracellular ATP levels were measured using CellTiter-Glo Luminescent Cell Viability Assay (G7571, Promega) following the manufacturer's instructions. Cells were seeded at a concentration of 160,000 cells in white opaque-bottom, 96 -well plates, with a final volume of $50 \mu \mathrm{L}$ per well and treated or not with $3 \mu \mathrm{M}$ oligomycin or $50 \mathrm{mM}$ 2-Deoxyglucose (2-DG). After $3 \mathrm{~h}, 50 \mu \mathrm{L}$ CellTiter-Glo® Reagent (CellTiter-Glo Buffer + CellTiter-Glo Substrate) was added to the cells. Contents were mixed for $2 \mathrm{~min}$ on an orbital shaker to induce cell lysis and, after 10 min of incubation at $22^{\circ} \mathrm{C}$, the luminescence signal was monitored in a Biotek Cytation 3 spectrophotometer (BioTek Instruments Inc., USA). The luminescence signal was proportional to the amount of ATP present in the solution [52], interpolated into the ATP standard curve prepared following the manufacturer's instructions.

\section{Lactate levels}

Extracellular lactate levels were determined colorimetrically using the L-Lactate Assay Kit (LC2389, Randox), as recommended by the manufacturer. In this assay, lactate is oxidized by lactate oxidase to generate pyruvate and $\mathrm{H}_{2} \mathrm{O}_{2}$, which reacts with 4-aminoantipyrine and N-ethyl-N-(2-hydroxy-3-sulphopropyl)-mtoluidine to produce a purple product proportional to the amount of lactate. Lymphoblasts were seeded at a concentration of $3.2 \times 10^{6} \mathrm{cells} / \mathrm{mL}$ in 12 -well plates, with a final volume of $1 \mathrm{~mL}$ per well and treated with $3 \mu \mathrm{M}$ oligomycin. After $24 \mathrm{~h}$, the cell suspension was centrifuged at $300 \times \mathrm{g}$ for $5 \mathrm{~min}$ at $4{ }^{\circ} \mathrm{C}$, and the supernatant was collected. The kit reagent was added to the supernatant and incubated $5 \mathrm{~min}$, at $37^{\circ} \mathrm{C}$. The absorbance was measured at $550 \mathrm{~nm}$ in a Biotek Cytation 3 spectrophotometer (BioTek Instruments Inc., USA). A lactate standard curve was performed following the manufacturer's instructions.

\section{Lactate dehydrogenase (LDH) activity}

LDH activity was spectrophotometrically measured using pyruvate and NADH as substrates, according to [53]. Total cellular extracts were obtained from a volume of cell suspension containing $30 \times 10^{6}$ cells of each sample, centrifuged at $259 \times \mathrm{g}$, at room temperature, for 5 min. The supernatant was discharged, and the resulting pellet was washed in PBS with $0.5 \%(\mathrm{v} / \mathrm{v})$ Triton X-100. The samples were submitted to 3 cycles of freezing in liquid nitrogen and then centrifuged at $12000 \mathrm{xg}$, for $10 \mathrm{~min}$. The protein content of each sample was then determined by the bicinchoninic acid method (BCA; 4,4'-dicarboxi-2,2'biquinoline) [54]. Briefly, $0.5 \mu \mathrm{g}$ of each sample was incubated in reaction buffer containing: $25 \mathrm{mM}$ of Tris- $\mathrm{NaCl}, \mathrm{pH}=8$ and $1.464 \mathrm{mM}$ monosodic pyruvate, at $37^{\circ} \mathrm{C}$, and enzymatic activity was followed by the decrease in the absorbance at $340 \mathrm{~nm}$ due to the oxidation of NADH, upon the addition of $0.0732 \mathrm{mM}$ $\mathrm{NADH}$, for $5 \mathrm{~min}$ in a VICTOR Multilabel Plate Reader (Perkin Elmer,Inc.,Waltham, MA, USA). LDH activity was determined by using an $\varepsilon 340 \mathrm{~nm}=0.63$ $\mathrm{mM}^{-1} \mathrm{~mm}^{-1}$ by subtracting the basal and the reaction slopes (i.e., in the absence and presence of NADH). Results were expressed as \%/(control).

\section{Hexokinase activity}

Hexokinase activity was spectrophotometrically measured based on the reduction of NADP ${ }^{+}$to NADPH, which occurs during the phosphorylation of glucose into glucose-6-phosphate (Bergmeyer H.U. et al., 1983). The cellular extracts were prepared as described in the determination of LDH activity. In this assay, 20 $\mu \mathrm{g}$ of each sample was incubated in reaction buffer containing: $37.94 \mathrm{mM}$ Tris- $\mathrm{NaCl} \mathrm{pH=8,10} \mathrm{mM} \mathrm{MgCl}, 1.1 \mathrm{mM} \mathrm{ATP}, 1.2 \mathrm{mM} \mathrm{NADP}+, 2 \mathrm{U} / \mathrm{mL}$ glucose 6phosphate dehydrogenase. The enzymatic activity was measured by following at $340 \mathrm{~nm}$ the reduction of NADP $\mathrm{P}^{+} 37^{\circ} \mathrm{C}$, after adding of $216 \mathrm{mM}$ glucose for $5 \mathrm{~min}$ in a VICTOR Multilabel Plate Reader (Perkin Elmer, Waltham, MA, USA). Hexokinase activity was determined using an $\varepsilon 340 \mathrm{~nm}=0.63 \mathrm{mM}^{-1} \mathrm{~mm}^{-1}$, by subtracting the basal and the reaction slopes (i.e., in the absence and presence of glucose). Results were expressed as \%/(control).

\section{Computational data analysis}

Orange 3.27.1 [55] was used for the computational data analysis and visualization. Features were ranked regarding entropy-based the Information Gain between each individual feature and the targets. Five targets were considered to be relevant for the analysis: Group (Control, undSOD1, mutSOD1), Disease

Page 6/20 
(Control, ALS), Mutation (No mutSOD1, mutSOD1), Sex (Male, Female) and Age (26/27 y old, 46 y old). The top 3 features and any additional attributes with identical information gain values were considered for their potential to distinguish samples according to the targets. Linear projections were generated for the selected features after applying principal component analysis (PCA) for dimensionality reduction. As the selected features provided a good visual separation between the experimental classes, we used them to train a Naïve Bayes classifier model, using leave-one-out cross-validation. Performance evaluation was based on confusion matrices, representing the number of true positives (TP), true negatives (TN), false positives (FP) and false negatives (FN) in percent of the total real instances for each class. The following metrics were calculated: Area Under the Curve (AUC), Precision = TP $/(T P+F P) ; R e c a l l=T P /(T P+F N)$; F1 score $=2 \times(($ Precision $\times$ Recall $) /($ Precision + Recall $))$, and Classification Accuracy $(C A)=(T P+T N) /(T P+T N+F P+F N)$.

\section{Statistics}

Paired and pooled statistical analyses were performed using GraphPad Prism 8.02 software (GraphPad Software, Inc., San Diego, California, USA).

Data are represented in bar graphs (mean \pm SEM) with dot plots for the number of experiments indicated in figure legends. Statistical significance was set at $\mathrm{P}<0.05$ and determined by the Kruskal Wallis method, followed by Dunn's multiple comparisons test.

\section{Results}

\section{Mitochondrial respiration and glycolytic fluxes}

The mitochondrial function and metabolic profile of lymphoblasts from ALS patients and age and sex matching controls were evaluated by measuring the oxygen consumption rate (OCR) and extracellular acidification rate (ECAR) using the Agilent-Seahorse XFe96 analyzer. Modulators of mitochondrial respiration ( $3 \mu \mathrm{M}$ Oligomycin, $0.25 \mu \mathrm{M}$ FCCP, and $1 \mu \mathrm{M}$ Rotenone/Antimycin A) were sequentially added to determine basal respiration, oxygen consumption associated with ATP synthesis, maximal respiration, and oxygen consumption associated with proton leak. The ECAR was simultaneously evaluated. From the individual analysis of each cohort, we observed for $\mathrm{C} 1$ (lymphoblast cells from 46 years old females) an increase in the proton leak-associated OCR and spare respiratory capacity in ALS patients with unknown SOD1 mutation (undSOD1), comparatively to the matched control (Fig. 1B and E). Interestingly, no significant differences were observed regarding basal respiration (Fig. 1A). Furthermore, an increase in baseline and stressed (after oligomycin and FCCP addition) ECAR was also observed in undSOD1, when compared with the control (Fig. 1G,H), suggesting that lymphoblasts from ALS patients with undSOD1 metabolically more active. Inside the same cohort, comparing lymphoblast from undSOD1 with lymphoblast from ALS patients with mutSOD1, the latter showed lower basal respiration, ATP production-driven OCR, maximal respiration, non-mitochondrial respiration, and bioenergetic health index, appearing to be metabolically more glycolytic.

From the cohort two (C2) analysis (lymphoblasts from 46 years old males), no statistically significant differences were observed in analyzed parameters between control and ALS patients. However, lower basal respiration, proton leak-associated OCR, maximal respiration, non-mitochondrial respiration, baseline ECAR and stressed ECAR were observed in lymphoblasts from mutSOD1 patients when compared with undSOD1 patients. In this cohort, lymphoblasts from mutSOD1 patients appear to be metabolically more quiescent than lymphoblasts from control and undSOD1.

Relatively to cohort three (C3) (lymphoblast cells from 26/27 years old males), a decrease in basal respiration, proton leak-associated OCR, ATP synthesisassociated OCR, baseline ECAR and stressed ECAR was observed, comparatively to lymphoblasts from controls (Fig. 1A,B,C,G,H). Compared with lymphoblasts from undSOD1, lower maximal respiration and spare respiratory capacity were observed in mutSOD1 (Fig. 1D,E). In this cohort, lymphoblasts from mutSOD1 patients appear to be metabolically more quiescent than control lymphoblasts (Fig. 1M).

Considering a pool of samples from all cohorts, we did not observe statistically significant differences in the analyzed parameters. High data variability and a low number of samples in each group are the possible reasons for the lack of statistical differences when performing this type of analysis.

\section{ATP-generating pathways}

After metabolic flux evaluations, we next measured the contribution of glycolysis and oxidative phosphorylation to ATP production. The cellular ATP production rate was quantified using Agilent Seahorse XF technology by sequentially inhibiting the ATP synthase with oligomycin and the mitochondrial ETC with rotenone and antimycin A. Lymphoblasts from undSOD1 ALS patients presented a higher ATP production rate derived from glycolysis, although only being statistically significant in cohort 1 and also when all cohorts were pooled together (Fig. 2B). The results observed in $\mathrm{C} 1$ are in agreement with the increased hexokinase activity (Fig. 2G), higher ATP levels without (Fig. 2K), and with oligomycin (Fig. 2L), and increased lactate levels (Fig. 2N). The data suggest that the glycolytic pathway has a high contribution to ATP production in lymphoblasts isolated from undSOD1ALS patients. In fact, in the presence of $50 \mathrm{mM}$ of 2-DG, a $66.7 \%$ reduction in ATP levels was observed in lymphoblasts from undSOD1 (Fig. 2M).

On the other hand, lymphoblasts from mutSOD1 patients presented a lower ATP production rate than undSOD1, being statistically significant in C2 and C3 (Fig. 2A), which matches their quiescent metabolic phenotype (Fig. 1L,M). In C1, the mitochondrial contribution to ATP production rate in mutSOD1 lymphoblasts was lower than in undSOD1 (Fig. 2C). Furthermore, in C1, the contribution of glycolysis for ATP production (Fig. 2E) and LDH activity (Fig. 2F) were higher in mutSOD1 than in controls. In fact, in C2, mutSOD1 lymphoblasts presented higher lactate levels (Fig. $2 \mathrm{~N}$ ), and in the presence of oligomycin, the lactate levels were higher in mutSOD1 for all cohorts (Fig. 20), showing a higher glycolytic capacity in this group of patients.

\section{Mitochondrial transcripts, biogenesis and membrane potential}

To further characterize how mutSOD1 and undSOD1 lymphoblasts differ in terms of mitochondrial biogenesis, we measured mitochondria-relevant transcripts and protein amount by qPCR and Western blotting, respectively, and mitochondrial membrane potential by flow cytometry. We demonstrated that transcripts of mitochondrial oxidative phosphorylation subunits in lymphoblasts from ALS patients of all cohorts were not significantly altered when compared to 
lymphoblasts from controls (Fig. 3A-F). However, transcripts for mitochondrial complex l-related subunit NDUFA9 (Fig. 3A) were increased in lymphoblasts from $\mathrm{C} 1$ and $\mathrm{C} 3$ mutSOD1 patients relative to the matched-controls counterparts. There were also increases in transcripts for cytochrome $\mathrm{c}$ (CYCS, Fig. 3D) in lymphoblasts from C3 mutSOD1 and cytochrome c oxidase subunit IV isoform 1 (COX4i1, Fig. 3E) in lymphoblasts from C1 mutSOD1 patients and C3 undSOD1 patients, compared to the respective controls. ATP5G1 transcripts were also increased in lymphoblasts from C3 undSOD1 patients (Fig. 3E, $\mathrm{F}$ ) relatively to control. No significant changes were observed between lymphoblasts from ALS patients and age and sex-matched controls regarding mitochondrial potential (Fig. 3G). Concerning mitochondrial biogenesis markers, our results showed that mitochondrial DNA copy number (Fig. 3H) and Tfam transcripts (Fig. 3I) did not change in lymphoblasts of ALS patients from all cohorts or for each cohort C1, C2 and C3, apart from a significant increase in mtDNA copy number in mutSOD1 from C3, when compared to undSOD1 (Fig. 3H). However, the protein levels of Tfam (Fig. 3J) were significantly decreased in lymphoblasts from undSOD1 patients when pooling samples or from individual C1 and C3 when compared to the respective controls, while the PGC1a and TOM20 protein levels did not significantly change between lymphoblasts from ALS patients and controls (Fig. 3K,L).

\section{Mitochondrial oxidation of TCA cycle substrates}

To analyze the disruption of mitochondrial metabolism in lymphoblasts from ALS patients with mutSOD1 and undSOD1, we performed a phenotypic metabolic analysis of TCA cycle substrates using the Biolog Mitoplate S1 system (Fig. S1 and Fig. 4). Considering the pooled analysis of all cohorts, we observed that the rate of oxidation of TCA cycle substrates between lymphoblasts from ALS patients and controls was not significantly altered (Fig. 4). Interestingly, by analyzing cohorts individually, our results showed that undSOD1 lymphoblasts from C1 presented lower oxidation rates of cis-aconitic acid (Fig. 4D), isocitric acid (Fig. 4E), a-ketoglutarate (Fig. 4F), L-malic acid (Fig. 4I), L-glutamic acid (Fig. 4J), L-glutamine (Fig. 4K) compared to control, while mutSOD1 from C1 presented lower oxidation rates of pyruvic acid (Fig. 4A), succinic acid (Fig. 4G) and fumaric acid (Fig. 4H) when compared with the respective matched-controls. undSOD1 lymphoblasts in C2 had lower oxidation rates of pyruvic acid (only in the presence of L-malic acid) (Fig. $4 A, B$ ), Lglutamic acid (Fig. 4J), L-glutamine (Fig. 4K), alanine-glutamine (Fig. 4L) with a higher rate of utilization of L-malic acid (Fig. 4I) compared to control. Curiously, undSOD1 in C3 presented higher oxidation rates of fumaric acid (Fig. 4H) and L-glutamine (Fig. 4K), while mutSOD1 showed a higher rate of oxidation of pyruvic acid (Fig. 4A), citric acid (Fig. 4C), and L-glutamic acid (Fig. 4J), relative to control. These results suggest a unique age-dependent oxidation rate profile of TCA cycle substrates in ALS patients with mutSOD1 and undSOD1.

\section{Mitochondrial oxidation of fatty acids, amino acids and cytosolic substrates}

Next, we analyzed the alterations of mitochondrial metabolism of fatty acids, amino acids and cytosolic substrates in lymphoblasts from ALS patients with mutSOD1 and undSOD1, using the same phenotypic metabolic analysis (Fig. S1 and Fig. 5).

Concerning the oxidation rates of fatty acids, amino acids and cytosolic substrates, among other compounds, in all cohorts, no significant variations were observed between lymphoblasts from ALS patients and controls (Fig. 5). Analyzing cohorts individually, we observed that lymphoblasts from C1 undSOD1 presented a lower rate of oxidation of octanoyl L-carnitine (+L-malic acid) (Fig. 5A), while lymphoblasts from C2 undSOD1 presented a higher rate of oxidation of octanoyl L-carnitine (+L-malic acid) (Fig. 5A) and palmitoyl L-carnitine (+L-malic acid) (Fig. 5B), compared to control. Regarding the individual analysis of cytosolic substrates by cohorts, our results showed that lymphoblasts from C1 undSOD1 presented a higher rate of oxidation of D-glucose-6-PO ${ }_{4}(\mathrm{Fig}$. 5E), and lymphoblasts from $\mathrm{C} 2$ undSOD2 presented higher rate oxidation of D-glucose-1- $\mathrm{PO}_{4}$, and a trend towards an increase in the rate of $\mathrm{D}$-glucose-6-PO ${ }_{4}$ oxidation (Fig. 5D,E), compared to respective controls. Lymphoblasts from C2 mutSOD1 presented a lower utilization capacity of D-gluconate-6-PO 4 (Fig. 5F), while lymphoblasts from C3 mutSOD1 presented a higher oxidation rate of D-glucose-1-PO ${ }_{4}, \mathrm{D}$-glucose-6-PO ${ }_{4}, \mathrm{D}-\mathrm{gluconate}-6-\mathrm{PO} \mathrm{O}_{4}$ and L-lactic acid (Fig. 5D,E,F,G), relative to control. Analyzing the rate of oxidation of amino acids and other substrates specifically by cohorts, our results showed a lower rate of oxidation of D-L-ß-hydroxybutyric acid (Fig. 5J) and L-leucine (+L-malic acid) (Fig. 5P) in lymphoblasts from C1 undSOD1, as well as a higher oxidative capacity of serine (Fig. 5N) and tryptamine (Fig. 5M) in lymphoblasts from C1 mutSOD1 compared to control and C1 undSOD1, respectively. Interestingly, we observed that lymphoblasts from undSOD1 in C3 presented a higher rate of oxidation of serine (Fig. 5N) and L-ornithine (Fig. 50), and lymphoblasts from mutSOD1 presented a higher rate of oxidation of tryptamine (Fig. $5 \mathrm{M}$ ) relatively to control. Acetylcarnitine and a-keto-isocaproic acid (plus L-malic acid) were not included in the data analysis because the corrected rates of dye reduction gave negative results, meaning that they were lower than the rates of dye reduction in the absence of substrate (Fig. S1).

\section{Integrative analysis}

To integrate all the results and understand which alterations are more characteristic of ALS lymphoblast metabolism and mitochondrial function fingerprinting, we performed multidimensional data analysis. Five factors (targets) were considered to be relevant for the analysis: Group (Control, undSOD1, mutSOD1), Disease (Control, ALS [undSOD1, mutSOD1]), Mutation (No mutSOD1 [Control, undSOD1], mutSOD1), Sex (Male, Female), and Age (26-27 y old, 46 $y$ old). The measured features were ranked regarding the information gain between each feature and the targets. The top 3 features, and any additional attributes with identical information gain values (Fig. 6A), were considered for their potential to distinguish samples according to the targets. Principal component analysis was applied for further dimensionality reduction, generating linear projections (Fig. 6B). The performance of a Naïve Bayes classifier model for target classification was also evaluated.

Considering group as a target, the features that contributed for a better segregation of Control, undSOD1 and mutSOD1 were found to be the protein levels of Tfam (Tfam_p) and glycolytic ATP production rate, followed by maximal and non-mitochondrial respirations, transcripts coding for cytochrome $\mathrm{C}$ (CYCs_mRNA), glucose-6-phosphate dehydrogenase (G6PD_mRNA) or pyruvate dehydrogenase A1 (PDHA1_mRNA), mitochondrial Alanine-Glutamine (AlaGIn) oxidation rates, glycolysis (percent of glycolytic ATP production) and intracellular ATP levels after treatment with 2-DG. The Naïve Bayes classifier was able to predict the samples belonging to each group perfectly. 
Considering disease as a target, Tfam_p had the highest information gain, followed by maximal respiration, mitochondrial oxidation of serine, extracellular lactate levels before and after treatment with oligomycin, LDH activity, glycolytic ATP production rate and glycolysis (percent of glycolytic ATP production). Although, visually, the separation between ALS and no ALS samples was apparently very good, the Naïve Bayes classifier failed to classify mutSOD1 from C1 and C2 as ALS, correctly predicting all the control and undSOD1 samples.

When considering mutation as a target, there were 9 features with the highest information gain, namely basal, proton leak-associated and non-mitochondrial respirations, baseline and stressed ECAR, glycolytic ATP production rate, protein levels of Tfam, transcripts coding for PDHA1 and intracellular ATP levels after treatment with 2-DG. The Naïve Bayes classifier was able to predict the samples belonging to mutation or non-mutation samples perfectly.

Regarding sex, 4 features had a high information gain, perfectly segregating female and male samples. These features included ATP production-associated respiration, mtDNA copy number, protein levels of PGC1a and transcripts encoding G6PD. The Naïve Bayes classifier was able to predict the samples belonging to male or female samples perfectly.

As for age, 10 features enabled a good separation between $26 / 27$ y old and 46 y old samples, including spare respiratory capacity, bioenergetic health index (BHI), transcripts coding for UQCRC2, ATP5G1 and Tfam, mtDNA copy number, mitochondrial oxidation of a-ketobutyric acid, total and mitochondrial ATP production rates and XF ATP Rate index. The Naïve Bayes classifier failed to classify the control and mutSOD1 from C2 as 46y old, having correctly predicted all the other samples.

\section{Discussion}

The present work identified unique mitochondrial and metabolic fingerprints in lymphoblasts from ALS patients with (mutSOD1) or without (undSOD1) known SOD1 mutations, compared with age- and sex-matched controls performing both pooled and paired comparisons.

Alterations in mitochondrial metabolism have been described in different ALS models. Mitochondrial dysfunction in ALS does not seem to be restricted to motor neurons, presenting also a systemic nature. In fact, metabolic changes associated with ALS pathology have been studied using other cells or tissue types obtained from patients, including fibroblasts [56, 47, 57-60], skeletal muscle biopsies [61] and peripheral blood mononuclear cells (PBMCs) [62]. The latter are interesting models since they are easy to collect in a mildly-invasive manner. Abnormalities of circulating blood cells may be a helpful prognostic or therapeutic biomarker in ALS.

ALS is a heterogeneous disease, presenting different rates of disease progression, patterns of spread, and various sites of onset between patients [63]. There are also various genetic mutations associated with ALS [64]. Thus, heterogeneity among the metabolism of circulating blood cells is also expected between patients, and it is reasonable to postulate that a single treatment strategy will not fit all patients, being imperative to identify small responder groups within larger patient populations $[65,66]$.

Similarly to fibroblasts, PBMCs can be used for cell reprogramming into cerebral organoids to study mitochondrial health in a more complex neuronal-like environment [67]. Preserved mitochondrial genetics, function, and treatment responses were found across PBMCs to iPSCs to cerebral organoids [67], suggesting that mitochondrial physiology of PMBCs can recapitulate neuronal mitochondrial properties from the donor. Although it is possible to measure multiple mitochondrial parameters even from cryopreserved PBMCs [68], the amount of sample obtained from a given patient is very limited. This is critical because ALS is a relatively rare and rapidly progressing fatal disease, qualifying as an orphan disease (ORPHA:803), limiting the number of patient samples obtained for analysis. An alternative is the use of lymphoblasts, immortalized PBMCs that can be obtained from biobanks such as the Coriell Institute. These cells proliferate in culture, allowing the measurement of multiple functional cellular parameters at different time points, and have also been previously used for studying mitochondrial function in other neurodegenerative diseases [69-71]. These cells can also be manipulated and challenged in vitro to highlight subclinical disease-retarded metabolic alterations. In ALS, mtSOD1 lymphoblasts were previously used to demonstrate the existence of hyper oxidized SOD1 with toxic properties in patient-derived cells and allowed the identification of common SOD1-dependent toxicity between mutant SOD1-linked familial ALS and a subset of SALS [72]. This result highlighted how lymphoblasts can provide opportunities for biomarker development, sub-classifying ALS, and designing more disease-modifying therapies [72]. Moreover, increased ROS levels were reported in lymphoblasts from familial ALS patients with SOD1 mutations compared with sporadic ALS and normal controls (spouses of ALS patients), although the ROS generation was not directly correlated with SOD1 activity [72]. In the present work, we investigated several metabolic and mitochondrial hallmarks in lymphoblasts from each ALS patient and, although a high heterogeneity of metabolic data was found, we identified specific metabolic and mitochondrial alterations that may have a diagnostic and therapeutic interest.

\section{Metabolic hallmarks of ALS}

To find metabolic hallmarks of ALS, we compared lymphoblasts from ALS patients with matched controls. No common changes between mutSOD1 vs control and undSOD1 vs control were evident from our data, following conventional data analysis. However, multidimensional analysis considering "Disease" (ALS versus no ALS) as a target factor identified a possible pattern, mainly involving decreased Tfam protein levels (the feature with highest information gain) in lymphoblasts from individuals with ALS, regardless of SOD1 mutation, compared to controls. Tfam is a nuclear-encoded mitochondrial transcription factor involved in mtDNA genome maintenance, transcription, and replication [73]. Changes in Tfam expression have been found in several neurodegenerative diseases [74]. In SALS, a decrease in Tfam expression was also observed in PBMC obtained from patients [62]. ALS spinal neurons were found to present varied and reduced mtDNA gene copy numbers and increased mtDNA gene deletions [75], suggesting that the therapeutic use of human recombinant Tfam could be beneficial in ALS. In agreement, Tfam overexpression was shown to protect motor neurons in mutSOD1 ALS mice [76].

In our work, both groups of ALS lymphoblasts showed markers of hypermetabolism. In the pooled analysis, undSOD1 lymphoblasts were characterized by increased glycolytic ATP rate and decreased Tfam protein levels compared to matched controls. Moreover, although not statistically significant in the pooled

Page $9 / 20$ 
analysis, all mutSOD1 cells showed increased extracellular lactate levels after challenge with oligomycin, compared to the respective controls. The data is consistent with the higher metabolic plasticity of mutSOD1 under mitochondrial stress (except in the youngest cohort) visible in the Seahorse Extracellular Flux Analyzer energy maps. Our data is consistent with the literature. It was previously shown that muscle atrophy and reduced physical activity in ALS coexists with a paradoxical increase in energy expenditure (hypermetabolism) [77]. Hypermetabolism in ALS patients is described as an early and persistent phenomenon [78], associated with more significant functional decline and shorter survival [79].

\section{Specific hallmarks of ALS associated with the SOD1 mutation (mutSOD1 vs undSOD1)}

To analyze the impact of mutSOD1 in ALS metabolic phenotype, we focused on the differences between mutSOD1 and undSOD1 lymphoblasts. Although no evident changes were found in the pooled analysis, paired analysis evidenced lower maximal respiration in mutSOD1 samples from all cohorts compared to the undSOD1 samples. Similar alterations were previously found in mutSOD1 models, including lower maximal respiration and reserve capacity in SOD1G93A mouse fibroblasts, compared to wild-type controls, with no variations in basal or ATP-linked respiration and no change in proton leak respiration [80]. A decrease in spare respiratory capacity was also found in fibroblasts from mutSOD1 patients compared to controls [58]. Moreover, a shift of energy generation from oxidative phosphorylation to glycolysis was observed in fibroblasts from mutSOD1 (1113T) patients [58]. Although glycolytic flux was upregulated in mutSOD1 fibroblasts, these cells did not increase their glycolytic capacity upon challenge with oligomycin, suggesting that they were already using their maximal glycolytic capacity [58]. Human mutSOD1 was previously shown to cause oxidative phosphorylation dysfunction in mitochondria of transgenic mice [25]. However, the decrease in maximal respiration observed in mutSOD1 compared to undSOD1 lymphoblasts seems to be due to a compensatory (although non-statistically significant) increase in maximal respiration in undSOD1 (but not in mutSOD1) compared to controls. This difference between undSOD1 and mutSOD1 lymphoblasts is likely related with the mitochondrial localization of mutSOD1 [32, 33]. Metabolic reprogramming was also observed in skin fibroblasts obtained from ALS patients and motor neurons from pre-symptomatic SODG93A mice, and conserved changes were found in protein translation, folding and assembly, tRNA aminoacylation, and cell adhesion processes [56].

A previous study aimed at identifying and distinguishing two subgroups of ALS patients from control subjects, using mitochondria from skin fibroblasts obtained from sALS, fALS, and control donors, found different mitochondrial bioenergetic profiles, despite the small number of samples used and the high variability in the measured parameters [57]. Among the variables analyzed in this study, fALS samples (3 with SOD1 and 1 with C90rf72 mutations) were characterized by a high maximal respiration rate in the presence of substrates for complexes I and II and under permeabilized conditions. High levels of the complex I NDUFB8 subunit were also found in mitochondria from fALS fibroblasts. In turn, mitochondria from sALS fibroblasts (with no mutations identified) were characterized by high flux control coefficient (Ci) for complexes I and IV. Mitochondria from control fibroblasts were mainly characterized by higher levels of SOD1 protein compared to their ALS counterparts [57].

\section{Impact of age and sex}

Since ALS is a rare disease, our experimental strategy overcomes the limitation of a starting low number of lymphoblasts samples by using an integrated multi-parametric analysis. Despite the complexity of simultaneous assays and the low statistical power to distinguish age and sex effects, our study showed clear disease-related differences. For example, samples from the youngest cohort (C3) presented different metabolic behaviors than the other two cohorts. Interestingly, in skin fibroblasts from donors of different ages, aging has been associated with respiratory function decline, mtDNA mutations, oxidative stress, and altered gene expression [81]. However, it is important to note that changes observed in the younger ALS patients can either be due to their younger age or to the earlier onset of the disease. In agreement with our above-described findings, age-related changes in bioenergetic properties and mitochondrial morphology were also found in fibroblasts from sALS patients, compared to fibroblasts from control donors [82]. A metabolic profiling study using Biolog plates in fibroblasts and induced neuronal progenitor cell derived iAstrocytes from C9orf72, TDP-43, SOD1 and sporadic ALS patients showed several metabolic alterations in patients, namely an age-dependent decrease in glycogen metabolism and in NADH production from different substrates [60]. NADH production resulting from glycogen metabolism in fibroblasts from familial cases was negatively correlated with end-points of disease severity including the age of onset and the age of death, while glucose-1-phosphate and D-fructose-6-phoshate negatively correlated with disease duration in the familial cohort [60]. This suggests that disrupted cellular metabolism is relevant and can be used to predict ALS progression.

Multidimensional analysis performed in this work using sex as the target variable identified 6 variables that allowed the distinction of male and female samples, including ATP production, mtDNA copy number, the levels of PGC1a and transcripts for the metabolic enzyme glucose-6-phosphate dehydrogenase. Sex-associated differences in mitochondrial function were also previously found in human PBMCs [83], highlighting the need for proper sex and age-matched controls for this type of study. Interestingly, glucose 6-phosphate dehydrogenase levels and activity were previously found to partially explain the impact of donor sex, age, and ethnicity on red blood cell antioxidant metabolism [84].

\section{Conclusions}

The results from this study revealed metabolic and mitochondrial parameters in lymphoblasts from ALS patients that can be promising biomarkers for disease stratification or further exploited as therapeutic targets for personalized ALS drug development.

\section{Abbreviations}

2-DG

$\Delta \Psi \mathrm{m}$

Ala-GIn
2-Deoxyglucose

Mitochondrial Membrane Potential 


\begin{tabular}{|c|c|}
\hline ALS & Amyotrophic Lateral Sclerosis \\
\hline BCA & Bicinchoninic Acid method \\
\hline Bcl-2 & B-Cell Lymphoma 2 \\
\hline $\mathrm{BHI}$ & Bioenergetic Health Index \\
\hline CNS & Central Nervous System \\
\hline CoX4i1 & Cytochrome c Oxidase Subunit IV Isoform 1 \\
\hline CYCS & Cytochrome c, Somatic \\
\hline CYCs_mRNA & Transcripts Coding for Cytochrome c, Somatic \\
\hline DTT & Dithiothreitol \\
\hline ECAR & Extracellular Acidification Rate \\
\hline EDTA & Ethylenediaminetetraacetic acid \\
\hline EGTA & Ethyleneglycol-bis (2-aminoethylether) N, N,'N, 'N-Tetraacetic Acid \\
\hline ETC & Mitochondrial Electron Transport Chain \\
\hline fALS & Familial ALS \\
\hline $\mathrm{FN}$ & False Negatives \\
\hline FP & False Positives \\
\hline G6PD_mRNA & Transcripts Coding for Glucose-6-phosphate Dehydrogenase \\
\hline HRP & Horseradish Peroxidase \\
\hline IMS & Mitochondrial Intermembrane Space \\
\hline LDH & Lactate Dehydrogenase \\
\hline MAS & Biolog Mitochondrial Assay Solution \\
\hline mutSOD1 & Mutant SOD1 \\
\hline NAM & Nicotinamide \\
\hline NDUFA9 & NADH:Ubiquinone Oxidoreductase Subunit A9 \\
\hline OCR & Oxygen Consumption Rate \\
\hline OMM & Outer Mitochondrial Membrane \\
\hline PBMCs & Peripheral Blood Mononuclear Cells \\
\hline PBS & Phosphate-Buffered Saline \\
\hline PCA & Principal Component Analysis \\
\hline PDHA1_mRNA & Transcripts Coding for Pyruvate Dehydrogenase A1 \\
\hline PMSF & Phenylmethanesulfonylfluoride \\
\hline sALS & Sporadic ALS \\
\hline SDS & Sodium Dodecyl Sulfate \\
\hline SOD1 & Cu/Zn Superoxide Dismutase 1 \\
\hline $\mathrm{Ta}$ & Annealing Temperature \\
\hline TBS-T & Tris-Buffered Saline Tween \\
\hline
\end{tabular}




$\begin{array}{ll}\text { Tfam_p } & \text { Protein Levels of Tfam } \\ \text { TMRM } & \text { Tetramethylrhodamine Methyl Ester Perchlorate } \\ \text { TN } & \text { True Negatives } \\ \text { TP } & \text { True Positives } \\ \text { undSOD1 } & \text { Unknown (or Undetermined) SOD1 Mutation } \\ \text { VDAC } & \text { Voltage-Dependent Anion-Selective Channel }\end{array}$

\section{Declarations}

Funding

This work was financed by the European Regional Development Fund (ERDF), through the COMPETE 2020 - Operational Programme for Competitiveness and Internationalization and Portuguese national funds via FCT - Fundação para a Ciência e a Tecnologia, under projects, PTDC/MED-FAR/29391/2017, P0CI-010145-FEDER-029391, PTDC/BTM-SAL/29297/2017, POCI-01-0145-FEDER-029297, PTDC/BTM-ORG/0055/2021, DL57/2016/CP1448/CT0016 [TCO], CEECIND/00322/2017 [EF], UIDP/04539/2020, UIDB/04539/2020 and UIDB/00081/2020. DM was supported by MSc Contract Mito4ALS - PTDC/MEDFAR/29391/2017.

Competing interests

The authors declare that they have no known competing financial interests or personal relationships that could have appeared to influence the work reported in this paper.

Author contributions

Filomena S.G Silva, Marcelo Carvalho, Elisabete Ferreiro and Débora Mena performed experiments. Filomena S. G. Silva, Teresa Cunha-Oliveira and Paulo J. Oliveira designed research and acquired funding. Filomena S. G. Silva, Teresa Cunha-Oliveira, Vilma Sardão and Francisco B. Pereira analyzed data. Filomena S. G. Silva, Vilma Sardão, Elisabete Ferreiro, Teresa Cunha-Oliveira and Paulo J. Oliveira wrote the paper. Fenanda Borges acquired funding and wrote the paper. Teresa Cunha-Oliveira prepared the figures. All authors read and approved the final manuscript.

Ethics approval and consent to participate

Not applicable.

Consent to participate

Not applicable.

Consent to publish

Not applicable.

Availability of data and material

The full datasets obtained during the current study are available from the corresponding author on reasonable request.

\section{References}

1. Longinetti E, Fang F (2019) Epidemiology of amyotrophic lateral sclerosis: an update of recent literature. Curr Opin Neurol 32 (5):771-776. doi:10.1097/WC0.0000000000000730

2. Dhasmana S, Dhasmana A, Narula AS, Jaggi M, Yallapu MM, Chauhan SC (2021) The panoramic view of amyotrophic lateral sclerosis: A fatal intricate neurological disorder. Life Sci 288:120156. doi:10.1016/j.Ifs.2021.120156

3. Julian TH, Boddy S, Islam M, Kurz J, Whittaker KJ, Moll T, Harvey C, Zhang S, Snyder MP, McDermott C, Cooper-Knock J, Shaw PJ (2021) A review of Mendelian randomization in amyotrophic lateral sclerosis. Brain. doi:10.1093/brain/awab420

4. Wijesekera LC, Leigh PN (2009) Amyotrophic lateral sclerosis. Orphanet J Rare Dis 4:3. doi:10.1186/1750-1172-4-3

5. Zarei S, Carr K, Reiley L, Diaz K, Guerra O, Altamirano PF, Pagani W, Lodin D, Orozco G, Chinea A (2015) A comprehensive review of amyotrophic lateral sclerosis. Surg Neurol Int 6:171. doi:10.4103/2152-7806.169561

6. Andrews JA, Jackson CE, Heiman-Patterson TD, Bettica P, Brooks BR, Pioro EP (2020) Real-world evidence of riluzole effectiveness in treating amyotrophic lateral sclerosis. Amyotroph Lateral Scler Frontotemporal Degener 21 (7-8):509-518. doi:10.1080/21678421.2020.1771734

Page $12 / 20$ 
7. Tanaka M, Sakata T, Palumbo J, Akimoto M (2016) A 24-week, phase III, double-blind, parallel-group study of edaravone (MCl-186) for treatment of amyotrophic lateral sclerosis (ALS)(P3. 189). AAN Enterprises,

8. Group TW, Group EALSS (2017) Safety and efficacy of edaravone in well defined patients with amyotrophic lateral sclerosis: a randomised, double-blind, placebo-controlled trial. Lancet Neurol 16 (7):505-512. doi:10.1016/S1474-4422(17)30115-1

9. Smith EF, Shaw PJ, De Vos KJ (2019) The role of mitochondria in amyotrophic lateral sclerosis. Neurosci Lett 710:132933. doi:10.1016/j.neulet.2017.06.052

10. Valdmanis PN, Rouleau GA (2008) Genetics of familial amyotrophic lateral sclerosis. Neurology 70 (2):144-152.

doi:10.1212/01.wnl.0000296811.19811.db

11. Bacman SR, Bradley WG, Moraes CT (2006) Mitochondrial involvement in amyotrophic lateral sclerosis: trigger or target? Mol Neurobiol 33 (2):113-131. doi:10.1385/MN:33:2:113

12. Palomo GM, Manfredi G (2015) Exploring new pathways of neurodegeneration in ALS: the role of mitochondria quality control. Brain Res $1607: 36-46$. doi:10.1016/j.brainres.2014.09.065

13. Cozzolino M, Carri MT (2012) Mitochondrial dysfunction in ALS. Prog Neurobiol 97 (2):54-66. doi:10.1016/j.pneurobio.2011.06.003

14. Appel SH, Beers DR, Zhao W (2021) Amyotrophic lateral sclerosis is a systemic disease: peripheral contributions to inflammation-mediated neurodegeneration. Curr Opin Neurol 34 (5):765-772. doi:10.1097/WC0.0000000000000983

15. Wiedemann FR, Winkler K, Kuznetsov AV, Bartels C, Vielhaber S, Feistner H, Kunz WS (1998) Impairment of mitochondrial function in skeletal muscle of patients with amyotrophic lateral sclerosis. J Neurol Sci 156 (1):65-72. doi:10.1016/s0022-510x(98)00008-2

16. Vielhaber S, Winkler K, Kirches E, Kunz D, Buchner M, Feistner H, Elger CE, Ludolph AC, Riepe MW, Kunz WS (1999) Visualization of defective mitochondrial function in skeletal muscle fibers of patients with sporadic amyotrophic lateral sclerosis. J Neurol Sci 169 (1-2):133-139. doi:10.1016/s0022-510x(99)00236-1

17. Nakano Y, Hirayama K, Terao K (1987) Hepatic ultrastructural changes and liver dysfunction in amyotrophic lateral sclerosis. Arch Neurol 44 (1):103-106. doi:10.1001/archneur.1987.00520130079022

18. Curti D, Malaspina A, Facchetti G, Camana C, Mazzini L, Tosca P, Zerbi F, Ceroni M (1996) Amyotrophic lateral sclerosis: oxidative energy metabolism and calcium homeostasis in peripheral blood lymphocytes. Neurology 47 (4):1060-1064. doi:10.1212/wnl.47.4.1060

19. Golpich M, Amini E, Mohamed Z, Azman Ali R, Mohamed Ibrahim N, Ahmadiani A (2017) Mitochondrial Dysfunction and Biogenesis in Neurodegenerative diseases: Pathogenesis and Treatment. CNS Neurosci Ther 23 (1):5-22. doi:10.1111/cns.12655

20. Boylan K (2015) Familial Amyotrophic Lateral Sclerosis. Neurol Clin 33 (4):807-830. doi:10.1016/j.ncl.2015.07.001

21. Deng HX, Hentati A, Tainer JA, lqbal Z, Cayabyab A, Hung WY, Getzoff ED, Hu P, Herzfeldt B, Roos RP, et al. (1993) Amyotrophic lateral sclerosis and structural defects in $\mathrm{Cu}, \mathrm{Zn}$ superoxide dismutase. Science 261 (5124):1047-1051. doi:10.1126/science.8351519

22. Kaur SJ, McKeown SR, Rashid S (2016) Mutant SOD1 mediated pathogenesis of Amyotrophic Lateral Sclerosis. Gene 577 (2):109-118. doi:10.1016/j.gene.2015.11.049

23. Rosen DR, Siddique T, Patterson D, Figlewicz DA, Sapp P, Hentati A, Donaldson D, Goto J, O'Regan JP, Deng HX, et al. (1993) Mutations in Cu/Zn superoxide dismutase gene are associated with familial amyotrophic lateral sclerosis. Nature 362 (6415):59-62. doi:10.1038/362059a0

24. Synofzik M, Ronchi D, Keskin I, Basak AN, Wilhelm C, Gobbi C, Birve A, Biskup S, Zecca C, Fernandez-Santiago R, Kaugesaar T, Schols L, Marklund SL, Andersen PM (2012) Mutant superoxide dismutase-1 indistinguishable from wild-type causes ALS. Hum Mol Genet 21 (16):3568-3574.

doi:10.1093/hmg/dds188

25. Mattiazzi M, D'Aurelio M, Gajewski CD, Martushova K, Kiaei M, Beal MF, Manfredi G (2002) Mutated human SOD1 causes dysfunction of oxidative phosphorylation in mitochondria of transgenic mice. J Biol Chem 277 (33):29626-29633. doi:10.1074/jbc.M203065200

26. Browne SE, Bowling AC, Baik MJ, Gurney M, Brown RH, Jr., Beal MF (1998) Metabolic dysfunction in familial, but not sporadic, amyotrophic lateral sclerosis. J Neurochem 71 (1):281-287. doi:10.1046/j.1471-4159.1998.71010281.x

27. Jung C, Higgins CM, Xu Z (2002) Mitochondrial electron transport chain complex dysfunction in a transgenic mouse model for amyotrophic lateral sclerosis. J Neurochem 83 (3):535-545. doi:10.1046/j.1471-4159.2002.01112.x

28. Kirkinezos IG, Bacman SR, Hernandez D, Oca-Cossio J, Arias LJ, Perez-Pinzon MA, Bradley WG, Moraes CT (2005) Cytochrome c association with the inner mitochondrial membrane is impaired in the CNS of G93A-SOD1 mice. J Neurosci 25 (1):164-172. doi:10.1523/JNEUROSCI.3829-04.2005

29. Menzies FM, Cookson MR, Taylor RW, Turnbull DM, Chrzanowska-Lightowlers ZM, Dong L, Figlewicz DA, Shaw PJ (2002) Mitochondrial dysfunction in a cell culture model of familial amyotrophic lateral sclerosis. Brain 125 (Pt 7):1522-1533. doi:10.1093/brain/awf167

Page $13 / 20$ 
30. Calabria E, Scambi I, Bonafede R, Schiaffino L, Peroni D, Potrich V, Capelli C, Schena F, Mariotti R (2019) ASCs-Exosomes Recover Coupling Efficiency and Mitochondrial Membrane Potential in an in vitro Model of ALS. Front Neurosci 13:1070. doi:10.3389/fnins.2019.01070

31. Bowling AC, Schulz JB, Brown RH, Jr., Beal MF (1993) Superoxide dismutase activity, oxidative damage, and mitochondrial energy metabolism in familial and sporadic amyotrophic lateral sclerosis. J Neurochem 61 (6):2322-2325. doi:10.1111/j.1471-4159.1993.tb07478.x

32. Jaarsma D, Rognoni F, van Duijn W, Verspaget HW, Haasdijk ED, Holstege JC (2001) CuZn superoxide dismutase (SOD1) accumulates in vacuolated mitochondria in transgenic mice expressing amyotrophic lateral sclerosis-linked SOD1 mutations. Acta Neuropathol 102 (4):293-305.

doi:10.1007/s004010100399

33. Higgins CM, Jung C, Ding H, Xu Z (2002) Mutant Cu, Zn superoxide dismutase that causes motoneuron degeneration is present in mitochondria in the CNS. J Neurosci $22(6): R C 215$

34. Liu J, Lillo C, Jonsson PA, Vande Velde C, Ward CM, Miller TM, Subramaniam JR, Rothstein JD, Marklund S, Andersen PM, Brannstrom T, Gredal O, Wong PC, Williams DS, Cleveland DW (2004) Toxicity of familial ALS-linked SOD1 mutants from selective recruitment to spinal mitochondria. Neuron 43 (1):5-17. doi:10.1016/j.neuron.2004.06.016

35. Bergemalm D, Jonsson PA, Graffmo KS, Andersen PM, Brannstrom T, Rehnmark A, Marklund SL (2006) Overloading of stable and exclusion of unstable human superoxide dismutase-1 variants in mitochondria of murine amyotrophic lateral sclerosis models. J Neurosci 26 (16):4147-4154.

doi:10.1523/JNEUROSCI.5461-05.2006

36. Deng HX, Shi Y, Furukawa Y, Zhai H, Fu R, Liu E, Gorrie GH, Khan MS, Hung WY, Bigio EH, Lukas T, Dal Canto MC, O'Halloran TV, Siddique T (2006) Conversion to the amyotrophic lateral sclerosis phenotype is associated with intermolecular linked insoluble aggregates of SOD1 in mitochondria. Proc Natl Acad Sci U S A 103 (18):7142-7147. doi:10.1073/pnas.0602046103

37. Vande Velde C, Miller TM, Cashman NR, Cleveland DW (2008) Selective association of misfolded ALS-linked mutant SOD1 with the cytoplasmic face of mitochondria. Proc Natl Acad Sci U S A 105 (10):4022-4027. doi:10.1073/pnas.0712209105

38. Pasinelli P, Belford ME, Lennon N, Bacskai BJ, Hyman BT, Trotti D, Brown RH, Jr. (2004) Amyotrophic lateral sclerosis-associated SOD1 mutant proteins bind and aggregate with Bcl-2 in spinal cord mitochondria. Neuron 43 (1):19-30. doi:10.1016/j.neuron.2004.06.021

39. Israelson A, Arbel N, Da Cruz S, Ilieva H, Yamanaka K, Shoshan-Barmatz V, Cleveland DW (2010) Misfolded mutant SOD1 directly inhibits VDAC1 conductance in a mouse model of inherited ALS. Neuron 67 (4):575-587. doi:10.1016/j.neuron.2010.07.019

40. Vijayvergiya C, Beal MF, Buck J, Manfredi G (2005) Mutant superoxide dismutase 1 forms aggregates in the brain mitochondrial matrix of amyotrophic lateral sclerosis mice. J Neurosci 25 (10):2463-2470. doi:10.1523/JNEUROSCI.4385-04.2005

41. Brand MD (2000) Uncoupling to survive? The role of mitochondrial inefficiency in ageing. Exp Gerontol 35 (6-7):811-820. doi:10.1016/s05315565(00)00135-2

42. Wiedemann FR, Manfredi G, Mawrin C, Beal MF, Schon EA (2002) Mitochondrial DNA and respiratory chain function in spinal cords of ALS patients. J Neurochem 80 (4):616-625. doi:10.1046/j.0022-3042.2001.00731.x

43. Verber NS, Shepheard SR, Sassani M, McDonough HE, Moore SA, Alix JJP, Wilkinson ID, Jenkins TM, Shaw PJ (2019) Biomarkers in Motor Neuron Disease: A State of the Art Review. Front Neurol 10:291. doi:10.3389/fneur.2019.00291

44. Vielhaber S, Kunz D, Winkler K, Wiedemann FR, Kirches E, Feistner H, Heinze HJ, Elger CE, Schubert W, Kunz WS (2000) Mitochondrial DNA abnormalities in skeletal muscle of patients with sporadic amyotrophic lateral sclerosis. Brain 123 ( Pt 7):1339-1348. doi:10.1093/brain/123.7.1339

45. Ghiasi P, Hosseinkhani S, Noori A, Nafissi S, Khajeh K (2012) Mitochondrial complex I deficiency and ATP/ADP ratio in lymphocytes of amyotrophic lateral sclerosis patients. Neurol Res 34 (3):297-303. doi:10.1179/1743132812Y.0000000012

46. Kirk K, Gennings C, Hupf JC, Tadesse S, D'Aurelio M, Kawamata H, Valsecchi F, Mitsumoto H, Groups APCS, Manfredi G (2014) Bioenergetic markers in skin fibroblasts of sporadic amyotrophic lateral sclerosis and progressive lateral sclerosis patients. Ann Neurol 76 (4):620-624. doi:10.1002/ana.24244

47. Konrad C, Kawamata H, Bredvik KG, Arreguin AJ, Cajamarca SA, Hupf JC, Ravits JM, Miller TM, Maragakis NJ, Hales CM, Glass JD, Gross S, Mitsumoto H, Manfredi G (2017) Fibroblast bioenergetics to classify amyotrophic lateral sclerosis patients. Mol Neurodegener 12 (1):76. doi:10.1186/s13024-017-0217-5

48. Li Q, Vande Velde C, Israelson A, Xie J, Bailey AO, Dong MQ, Chun SJ, Roy T, Winer L, Yates JR, Capaldi RA, Cleveland DW, Miller TM (2010) ALS-linked mutant superoxide dismutase 1 (SOD1) alters mitochondrial protein composition and decreases protein import. Proc Natl Acad Sci U S A 107 (49):2114621151. doi:10.1073/pnas. 1014862107

49. Perry SW, Norman JP, Barbieri J, Brown EB, Gelbard HA (2011) Mitochondrial membrane potential probes and the proton gradient: a practical usage guide. Biotechniques 50 (2):98-115. doi:10.2144/000113610

50. Bradford MM (1976) A rapid and sensitive method for the quantitation of microgram quantities of protein utilizing the principle of protein-dye binding. Anal Biochem 72:248-254. doi:10.1006/abio.1976.9999 
51. Romero-Calvo I, Ocon B, Martinez-Moya P, Suarez MD, Zarzuelo A, Martinez-Augustin O, de Medina FS (2010) Reversible Ponceau staining as a loading control alternative to actin in Western blots. Anal Biochem 401 (2):318-320. doi:10.1016/j.ab.2010.02.036

52. Mire-Sluis AR, Page L, Thorpe R (1995) Quantitative cell line based bioassays for human cytokines. J Immunol Methods 187 (2):191-199. doi:10.1016/0022-1759(95)00220-1

53. Bergmeyer HU, Bernt E (1974) UV-Assay with Pyruvate and NADH. In: Methods of Enzymatic Analysis. pp 574-579. doi:10.1016/b978-0-12-0913022.50010-4

54. Smith PK, Krohn RI, Hermanson GT, Mallia AK, Gartner FH, Provenzano MD, Fujimoto EK, Goeke NM, Olson BJ, Klenk DC (1985) Measurement of protein using bicinchoninic acid. Anal Biochem 150 (1):76-85. doi:10.1016/0003-2697(85)90442-7

55. Demšar J, Curk T, Erjavec A, Gorup Č, Hočevar T, Milutinovič M, Možina M, Polajnar M, Toplak M, Starič AJtJomLr (2013) Orange: data mining toolbox in Python. 14 (1):2349-2353

56. Szelechowski M, Amoedo N, Obre E, Leger C, Allard L, Bonneu M, Claverol S, Lacombe D, Oliet S, Chevallier S, Le Masson G, Rossignol R (2018) Metabolic Reprogramming in Amyotrophic Lateral Sclerosis. Sci Rep 8 (1):3953. doi:10.1038/s41598-018-22318-5

57. Walczak J, Debska-Vielhaber G, Vielhaber S, Szymanski J, Charzynska A, Duszynski J, Szczepanowska J (2019) Distinction of sporadic and familial forms of ALS based on mitochondrial characteristics. FASEB J 33 (3):4388-4403. doi:10.1096/fj.201801843R

58. Allen SP, Rajan S, Duffy L, Mortiboys H, Higginbottom A, Grierson AJ, Shaw PJ (2014) Superoxide dismutase 1 mutation in a cellular model of amyotrophic lateral sclerosis shifts energy generation from oxidative phosphorylation to glycolysis. Neurobiol Aging 35 (6):1499-1509.

doi:10.1016/j.neurobiolaging.2013.11.025

59. Raman R, Allen SP, Goodall EF, Kramer S, Ponger LL, Heath PR, Milo M, Hollinger HC, Walsh T, Highley JR, Olpin S, McDermott CJ, Shaw PJ, Kirby J (2015) Gene expression signatures in motor neurone disease fibroblasts reveal dysregulation of metabolism, hypoxia-response and RNA processing functions. Neuropathol Appl Neurobiol 41 (2):201-226. doi:10.1111/nan.12147

60. Gerou M, Hall B, Woof R, Allsop J, Kolb SJ, Meyer K, Shaw PJ, Allen SP (2021) Amyotrophic lateral sclerosis alters the metabolic aging profile in patient derived fibroblasts. Neurobiol Aging 105:64-77. doi:10.1016/j.neurobiolaging.2021.04.013

61. Echaniz-Laguna A, Zoll J, Ribera F, Tranchant C, Warter JM, Lonsdorfer J, Lampert E (2002) Mitochondrial respiratory chain function in skeletal muscle of ALS patients. Ann Neurol 52 (5):623-627. doi:10.1002/ana.10357

62. Araujo BG, Souza ESLF, de Barros Torresi JL, Siena A, Valerio BCO, Brito MD, Rosenstock TR (2020) Decreased Mitochondrial Function, Biogenesis, and Degradation in Peripheral Blood Mononuclear Cells from Amyotrophic Lateral Sclerosis Patients as a Potential Tool for Biomarker Research. Mol Neurobiol 57 (12):5084-5102. doi:10.1007/s12035-020-02059-1

63. Maniatis S, Aijo T, Vickovic S, Braine C, Kang K, Mollbrink A, Fagegaltier D, Andrusivova Z, Saarenpaa S, Saiz-Castro G, Cuevas M, Watters A, Lundeberg J, Bonneau R, Phatnani H (2019) Spatiotemporal dynamics of molecular pathology in amyotrophic lateral sclerosis. Science 364 (6435):89-93.

doi:10.1126/science.aav9776

64. Therrien M, Dion PA, Rouleau GA (2016) ALS: Recent Developments from Genetics Studies. Curr Neurol Neurosci Rep 16 (6):59. doi:10.1007/s11910-0160658-1

65. Goyal NA, Berry JD, Windebank A, Staff NP, Maragakis NJ, van den Berg LH, Genge A, Miller R, Baloh RH, Kern R, Gothelf Y, Lebovits C, Cudkowicz M (2020) Addressing heterogeneity in amyotrophic lateral sclerosis CLINICAL TRIALS. Muscle Nerve 62 (2):156-166. doi:10.1002/mus.26801

66. Katz JS, Barohn RJ, Dimachkie MM, Mitsumoto H (2015) The Dilemma of the Clinical Trialist in Amyotrophic Lateral Sclerosis: The Hurdles to Finding a Cure. Neurol Clin 33 (4):937-947. doi:10.1016/j.ncl.2015.07.014

67. Duong A, Evstratova A, Sivitilli A, Hernandez JJ, Gosio J, Wahedi A, Sondheimer N, Wrana JL, Beaulieu JM, Attisano L, Andreazza AC (2021) Characterization of mitochondrial health from human peripheral blood mononuclear cells to cerebral organoids derived from induced pluripotent stem cells. Sci Rep 11 (1):4523. doi:10.1038/s41598-021-84071-6

68. Masson JJR, Ostrowski M, Duette G, Lee MKS, Murphy AJ, Crowe SM, Palmer CS (2020) The Multiparametric Analysis of Mitochondrial Dynamics in T Cells from Cryopreserved Peripheral Blood Mononuclear Cells (PBMCs). Methods Mol Biol 2184:215-224. doi:10.1007/978-1-0716-0802-9_15

69. Naia L, Ferreira IL, Cunha-Oliveira T, Duarte Al, Ribeiro M, Rosenstock TR, Laco MN, Ribeiro MJ, Oliveira CR, Saudou F, Humbert S, Rego AC (2015) Activation of IGF-1 and insulin signaling pathways ameliorate mitochondrial function and energy metabolism in Huntington's Disease human lymphoblasts. Mol Neurobiol 51 (1):331-348. doi:10.1007/s12035-014-8735-4

70. Panov A, Obertone T, Bennett-Desmelik J, Greenamyre JT (1999) Ca(2+)-dependent permeability transition and complex I activity in lymphoblast mitochondria from normal individuals and patients with Huntington's or Alzheimer's disease. Ann N Y Acad Sci 893:365-368. doi:10.1111/j.17496632.1999.tb07856.x 
71. Annesley SJ, Lay ST, De Piazza SW, Sanislav O, Hammersley E, Allan CY, Francione LM, Bui MQ, Chen ZP, Ngoei KR, Tassone F, Kemp BE, Storey E, Evans A, Loesch DZ, Fisher PR (2016) Immortalized Parkinson's disease lymphocytes have enhanced mitochondrial respiratory activity. Dis Model Mech 9 (11):12951305. doi:10.1242/dmm.025684

72. Guareschi S, Cova E, Cereda C, Ceroni M, Donetti E, Bosco DA, Trotti D, Pasinelli P (2012) An over-oxidized form of superoxide dismutase found in sporadic amyotrophic lateral sclerosis with bulbar onset shares a toxic mechanism with mutant SOD1. Proc Natl Acad Sci U S A 109 (13):5074-5079. doi:10.1073/pnas. 1115402109

73. Gustafsson CM, Falkenberg M, Larsson NG (2016) Maintenance and Expression of Mammalian Mitochondrial DNA. Annu Rev Biochem 85:133-160. doi:10.1146/annurev-biochem-060815-014402

74. Kang I, Chu CT, Kaufman BA (2018) The mitochondrial transcription factor TFAM in neurodegeneration: emerging evidence and mechanisms. FEBS Lett 592 (5):793-811. doi:10.1002/1873-3468.12989

75. Keeney PM, Bennett JP, Jr. (2010) ALS spinal neurons show varied and reduced mtDNA gene copy numbers and increased mtDNA gene deletions. Mol Neurodegener 5:21. doi:10.1186/1750-1326-5-21

76. Morimoto N, Miyazaki K, Kurata T, Ikeda Y, Matsuura T, Kang D, Ide T, Abe K (2012) Effect of mitochondrial transcription factor a overexpression on motor neurons in amyotrophic lateral sclerosis model mice. J Neurosci Res 90 (6):1200-1208. doi:10.1002/jnr.23000

77. Ferri A, Coccurello R (2017) What is "Hyper" in the ALS Hypermetabolism? Mediators Inflamm 2017:7821672. doi:10.1155/2017/7821672

78. Bouteloup C, Desport JC, Clavelou P, Guy N, Derumeaux-Burel H, Ferrier A, Couratier P (2009) Hypermetabolism in ALS patients: an early and persistent phenomenon. J Neurol 256 (8):1236-1242. doi:10.1007/s00415-009-5100-z

79. Steyn FJ, loannides ZA, van Eijk RPA, Heggie S, Thorpe KA, Ceslis A, Heshmat S, Henders AK, Wray NR, van den Berg LH, Henderson RD, McCombe PA, Ngo ST (2018) Hypermetabolism in ALS is associated with greater functional decline and shorter survival. J Neurol Neurosurg Psychiatry 89 (10):1016-1023. doi:10.1136/jnnp-2017-317887

80. Pharaoh G, Sataranatarajan K, Street K, Hill S, Gregston J, Ahn B, Kinter C, Kinter M, Van Remmen H (2019) Metabolic and Stress Response Changes Precede Disease Onset in the Spinal Cord of Mutant SOD1 ALS Mice. Front Neurosci 13:487. doi:10.3389/fnins.2019.00487

81. Wei YH, Wu SB, Ma YS, Lee HC (2009) Respiratory function decline and DNA mutation in mitochondria, oxidative stress and altered gene expression during aging. Chang Gung Med J 32 (2):113-132

82. Allen SP, Duffy LM, Shaw PJ, Grierson AJ (2015) Altered age-related changes in bioenergetic properties and mitochondrial morphology in fibroblasts from sporadic amyotrophic lateral sclerosis patients. Neurobiol Aging 36 (10):2893-2903. doi:10.1016/j.neurobiolaging.2015.07.013

83. Silaidos C, Pilatus U, Grewal R, Matura S, Lienerth B, Pantel J, Eckert GP (2018) Sex-associated differences in mitochondrial function in human peripheral blood mononuclear cells (PBMCs) and brain. Biol Sex Differ 9 (1):34. doi:10.1186/s13293-018-0193-7

84. D'Alessandro A, Fu X, Kanias T, Reisz JA, Culp-Hill R, Guo Y, Gladwin MT, Page G, Kleinman S, Lanteri M, Stone M, Busch MP, Zimring JC, Recipient E, Donor Evaluation S, III (2021) Donor sex, age and ethnicity impact stored red blood cell antioxidant metabolism through mechanisms in part explained by glucose 6phosphate dehydrogenase levels and activity. Haematologica 106 (5):1290-1302. doi:10.3324/haematol.2020.246603

\section{Figures}



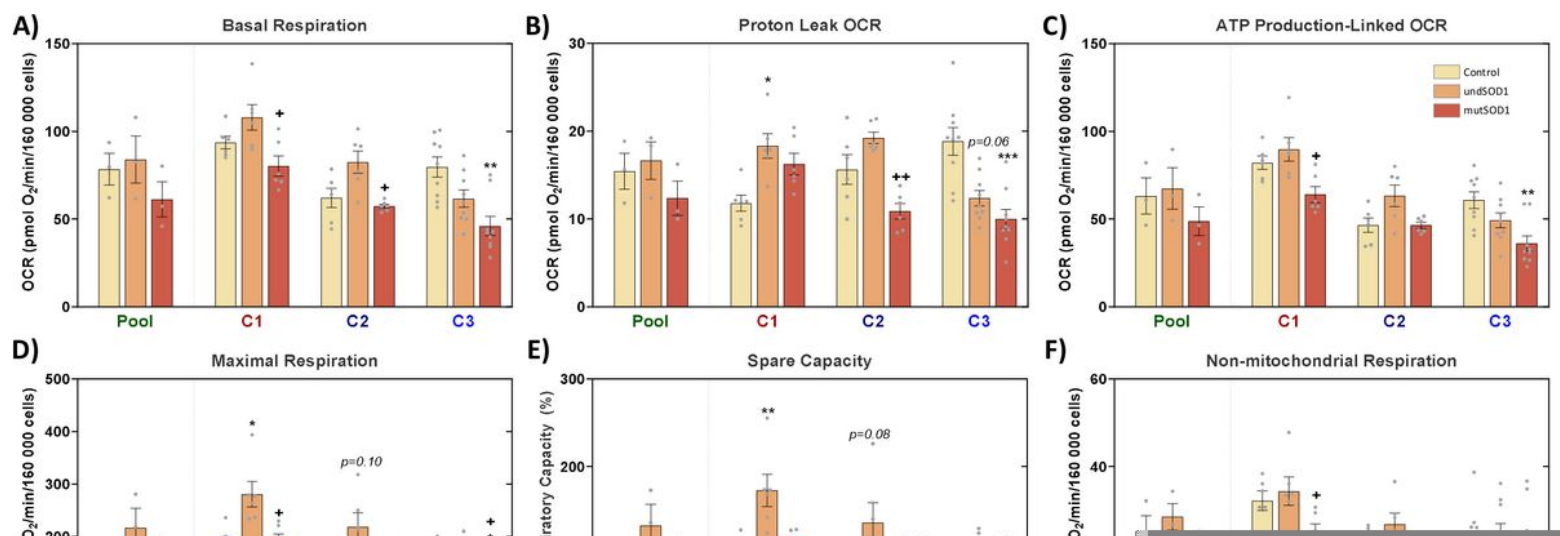

\section{Figure 1}

Oxygen consumption rate (OCR) and extracellular acidification rate (ECAR) parameters in lymphoblasts from ALS patients with mutant SOD1 (mutSOD1) and unknown mutation (undSOD1). Cells were plated at density 160,000 cells/well, as described in Materials and Methods. Mitochondrial Stress Test featuring OCR- and ECAR-associated parameters were assessed with the Seahorse XFe96 Extracellular Flux Analyzer. OCR and ECAR parameters, as well as energy maps showing the metabolic potential of cells. Data were plotted for all cohorts (pool), C1-Female 46 years old, C2- Male 46 years old and C3-Male 26/27 years old. OCR parameters evaluated: (A) Basal Respiration, (B) Proton Leak-associated OCR, (C) ATP production-linked OCR, (D) Maximal Respiration, (E) Spare Respiratory Capacity, and (F) Non-mitochondrial Respiration. ECAR parameters were also evaluated, including (G) Basal ECAR and (H) Stressed ECAR. (I) Bioenergetic Health Index (BHI) assesses the cellular bioenergetic health in lymphoblast from ALS patients with mutSOD1 and undSOD1 comparatively to controls, based on the OCR, according the equation: BHI= (Spare Respiratory Capacity x ATP production-linked OCR)/(Proton Leak OCR x Non-mitochondrial Respiration). (J) Energy maps evidence the metabolic potential of cells under basal or stress conditions. Data are the mean \pm SEM from at least 6 independent experiments. ${ }^{*} p<0.05,{ }^{* \star} p<0.01,{ }^{* \star *} p<0.01$ compared to respective control. $+p<0.05,++p<0.01$ compared to respective undSOD1 lymphoblasts.

\section{Figure 2}

Pathways associated with ATP production in lymphoblasts from ALS patients with mutant SOD1 (mutSOD1) or unknown mutation (undSOD1) and respective controls. Cells were plated at density 160,000 cells/well, as described in Materials and Methods. Oxygen consumption rate (OCR) and Extracellular Acidification Rate were monitored over time using the Seahorse XFe96 Extracellular Flux Analyzer and the ATP Real-Time rate assay. Data were plotted for all cohorts (pool), C1-Female 46 years old, C2- Male 46 years old and C3-Male 26/27 years old. Several bioenergetic parameters were evaluated: (A) Total ATP production rate, (B) Glycolytic ATP production rate, (C) Mitochondrial ATP production rate, (D) XF ATP Rate index and (E) \% Glycolysis. (F) Lactate dehydrogenase $(\mathrm{LDH})$ and $(\mathrm{H})$ hexokinase activities were determined using enzymatic assays. Transcripts for (I) glucose-6-phosphate dehydrogenase ( $G 6 P D)$, $(\mathrm{J})$ pyruvate dehydrogenase E1-alpha subunit (PDHA1) and (J) pyruvate dehydrogenase kinase 1 (PDK1) were measured and normalized to the geometric mean of TBP, YWHAZ, PUM1 and B2M (reference genes). Intracellular ATP levels were measured after $3 \mathrm{~h}$ of incubation in the (K) absence or $(\mathrm{L})$ presence of oligomycin or (M) 2-deoxyglucose (2-DG). Lactate levels were assessed in cells after $24 \mathrm{~h}$ incubation in the $(\mathrm{N})$ absence or $(0)$ presence of oligomycin. Data are the mean $\pm S E M$ from at least 6 independent experiments. ${ }^{*} p<0.05, * * p<0.01,{ }^{*} * *<<0.01$ compared to respective control. $+p<0.05,++p<0.01$ compared to respective undSOD1 lymphoblasts. 
A)

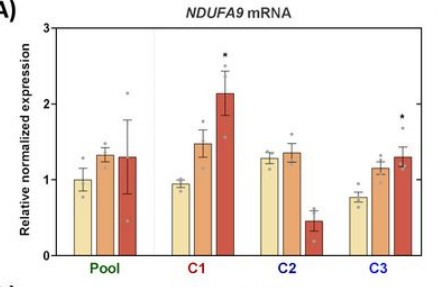

D)

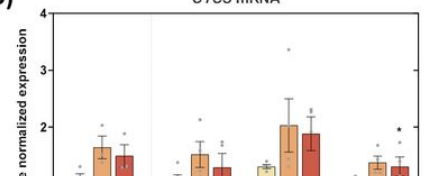

B)

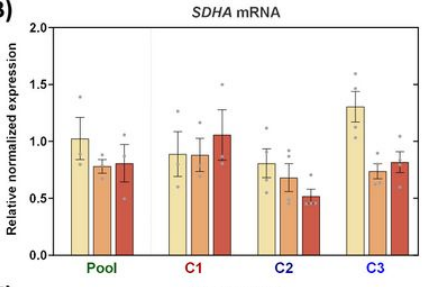

E)

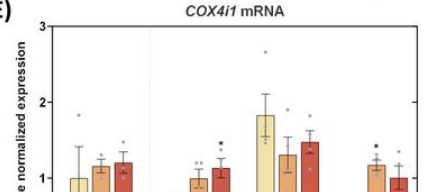

C)

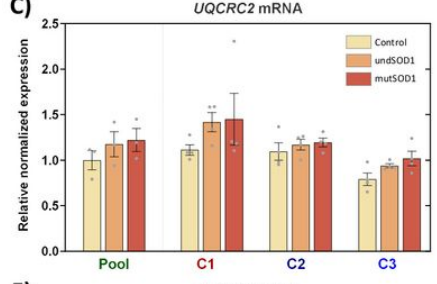

F)

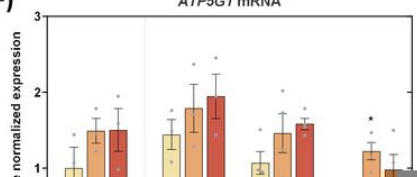

\section{Figure 3}

Mitochondrial respiratory chain subunits, biogenesis markers and mitochondrial membrane potential in lymphoblasts from ALS patients with mutant SOD1 (mutSOD1) or unknown mutation (undSOD1) and respective controls. Transcripts for (A-F) mitochondrial oxidative phosphorylation subunits and (I) mitochondrial biogenesis marker TFAM. Data were plotted for all cohorts (pool), C1-Female 46 years old, C2- Male 46 years old and C3-Male 26/27 years old. Gene expression was normalized to the geometric mean of TBP, YWHAZ, PUM1 and B2M. The mitochondrial potential (G) was measured by flow cytometry by subtracting the mean values of TMRM fluorescence in FCCP treated lymphoblast to the mean values of TMRM fluorescence. Mitochondrial DNA copy number was normalized to ND5 and B2m levels $(\mathrm{H})$. Western blot was used to semi-quantify protein expression levels of TFAM, PGC1a and TOM20 and protein normalization was performed by ponceau staining assay. Data are the mean \pm SEM from at least 6 independent experiments. ${ }^{*}<<0.05$ and ${ }^{*} p<0.01$ compared to respective control. $+p<0.05$ compared to respective undSOD 1 lymphoblasts. 

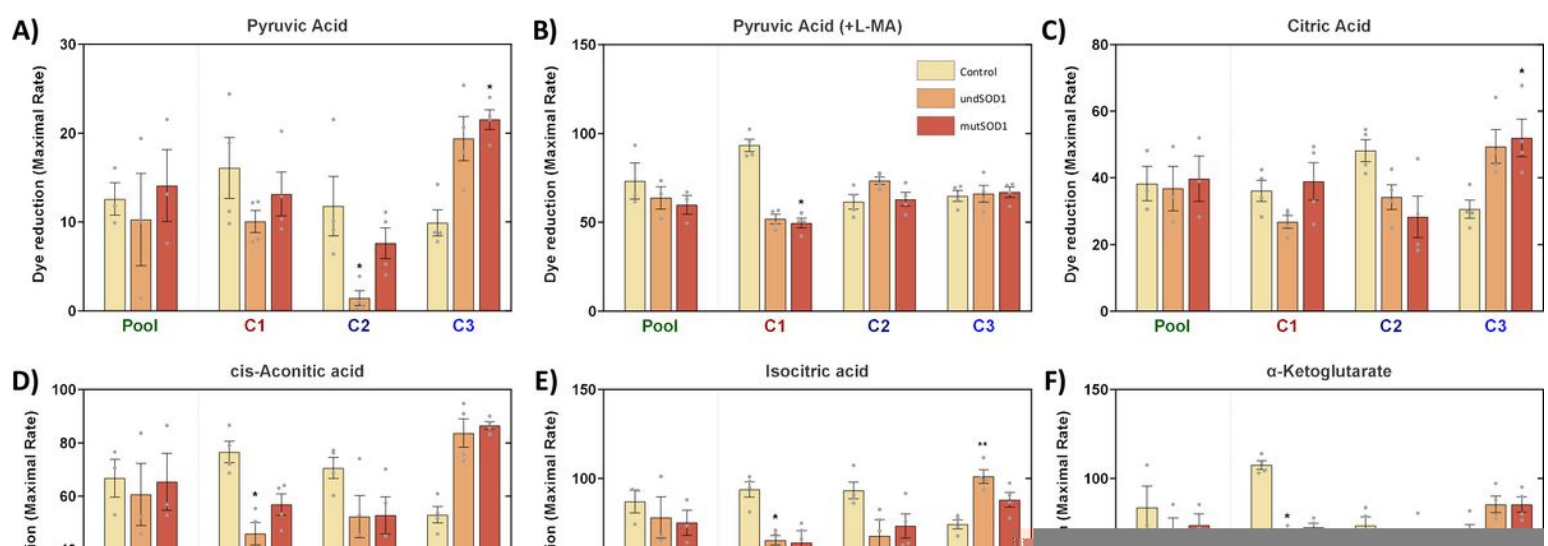

\section{Figure 4}

Mitochondrial oxidation of TCA cycle substrates in lymphoblasts from ALS patients with mutant SOD1 (mutSOD1) or unknown mutation (undSOD1) and respective controls. Cells were plated at density 160,000 cells/well, and the rate of oxidation of a panel of TCA cycle substrates was assessed using Biolog Mitoplate S1 assay. Data were obtained for all cohorts (pool), C1-Female 46 years old, C2- Male 46 years old and C3-Male 26/27 years old. The rate of oxidation of (A) pyruvic acid, (B) pyruvic acid + malic acid, (C) citric acid, (D) cis-aconitic acid, (E) isocitric acid, (F) a-ketoglutaric acid, (G) succinic acid, (H) fumaric acid, (I) L-malic acid, (J) L-glutamic acid, (K), L-glutamine and (L) alanine-glutamine. Data are the mean $\pm S E M$ from 4 independent experiments. ${ }^{*} p<0.05$ and ${ }^{* *} p<0.01$ compared to respective control. 
A)

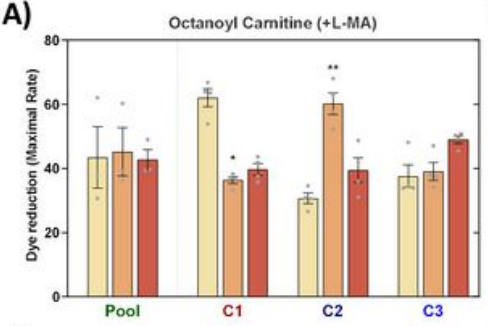

E)

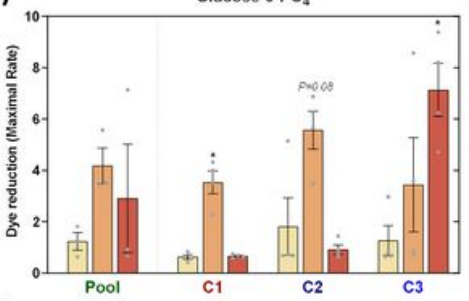

I)

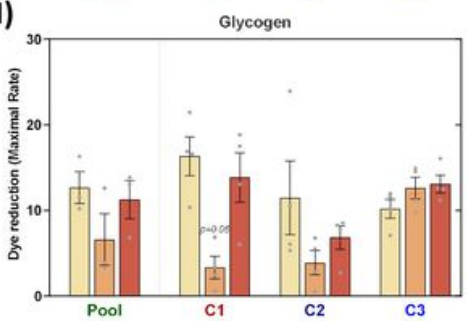

M)

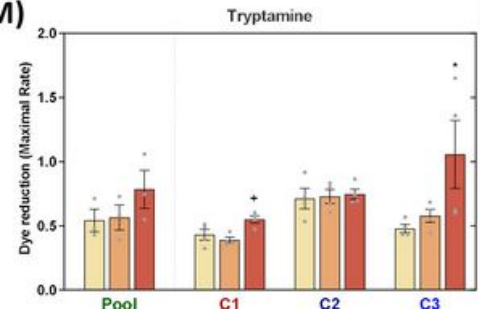

B)

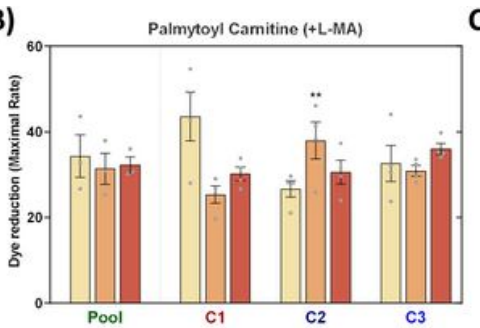

F)
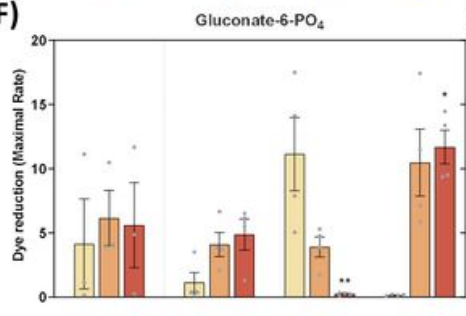

J)

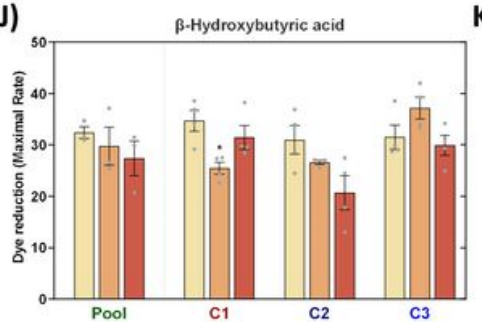

N)

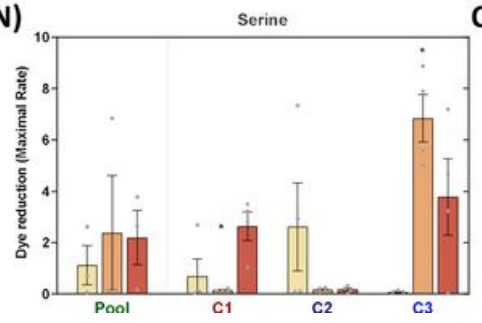

C)

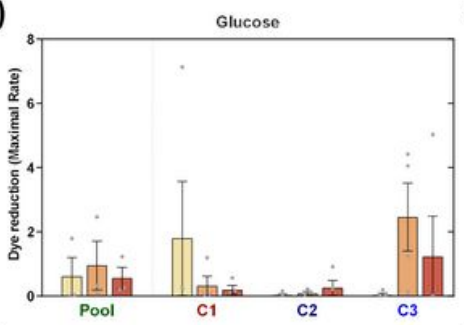

G)
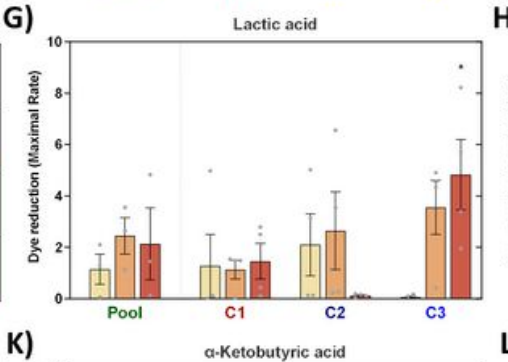

D)

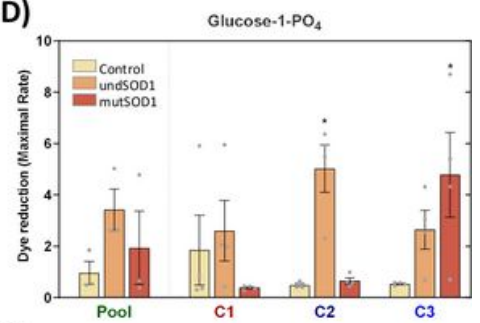

H)
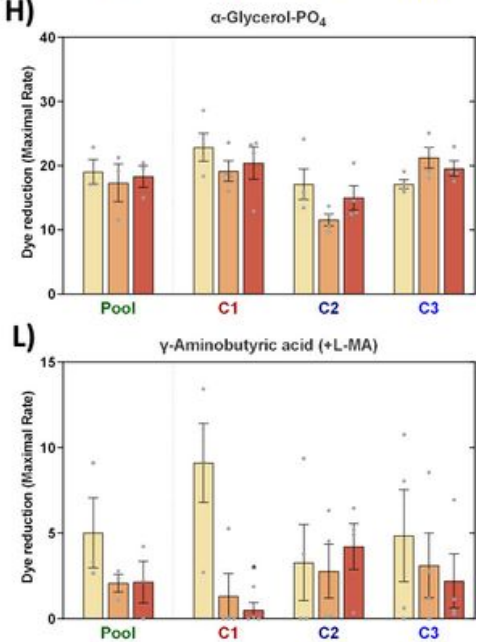

))

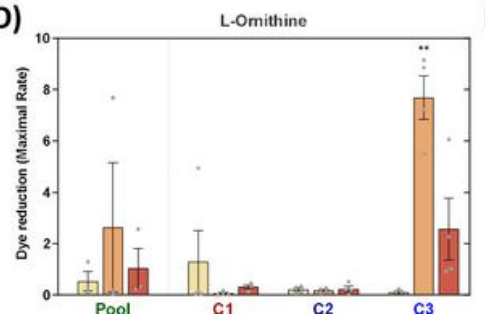

P)

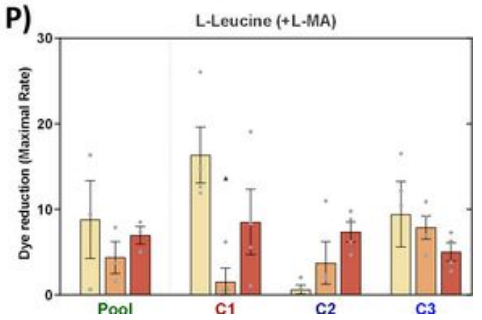

Figure 5

Mitochondrial oxidation of fatty acids, amino acids and other substrates in lymphoblasts from ALS patients with mutant SOD1 (mutSOD1) or unknown mutation (undSOD1) and respective controls. Cells were plated at density 160,000 cells/well, and the rate of oxidation of a panel of fatty acids, amino acids and other substrates was assessed using Biolog Mitoplate S1 assay. Data were plotted for all cohorts (pool), C1-Female 46 years old, C2- Male 46 years old and C3-Male 26/27 years old. The rate of oxidation of (A) octanoyl L-carnitine (+L-malic acid), (B) palmitoyl L-carnitine (+L-malic acid), (C) D-glucose, (D), Dglucose-1- $\mathrm{PO}_{4},(\mathrm{E})$ D-glucose-6- $\mathrm{PO}_{4},(\mathrm{~F})$ D-gluconate-6- $\mathrm{PO}_{4},(\mathrm{G})$ L-lactic acid, (H) D-L-a-glycerol-PO ${ }_{4}$ (I) glycogen, (J) D-L- $\beta$-hydroxybutyric acid, (K) a-ketobutyric acid, (L) $Y$-aminobutyric acid (+L-Malic acid), (M) tryptamine, $(\mathrm{N})$ serine, $(\mathrm{O}) \mathrm{L}$-ornithine, and $(\mathrm{P}) \mathrm{L}$-leucine (+L-malic acid). Data are the mean $\pm S E M$ from 4 independent experiments. ${ }^{*} p<0.05$ and ${ }^{* *} p<0.01$ compared to respective control, $+p<0.05$ compared to respective undSOD1 lymphoblasts.

\section{Figure 6}

Impact of different factors on lymphoblast metabolic profiles. A) Mutual Information (Information Gain) evidenced the features with more discriminative power between experimental conditions and enabled the selection of the 3 most discriminant features, and any other features with the same information gain for subsequent principal component analysis (PCA). We further evaluated the performance of a Naïve Bayes classifier with leave-one-out cross-validation using the selected features. Confusion matrices represent the number of true positives (TP), true negatives (TN), false positives (FP) and false negatives (FN) in percent of the total real instances for each class. The following metrics were calculated: Area Under the Curve (AUC); Classification Accuracy (CA) $=($ TP + $\mathrm{TN}) /(\mathrm{TP}+\mathrm{TN}+\mathrm{FP}+\mathrm{FN}) ; \mathrm{F} 1$ score $=2 \mathrm{x}(($ Precision $\times$ Recall $) /($ Precision + Recall $)) ;$ Precision = TP/(TP + FP $) ;$ Recall $=\mathrm{TP} /(\mathrm{TP}+\mathrm{FN})$.

\section{Supplementary Files}

This is a list of supplementary files associated with this preprint. Click to download.

\section{- SuppFig1.pdf}

